\title{
REVIEW
}

\section{Dendritic cells and their role in atherogenesis}

\author{
Yuri V Bobryshev
}

Dendritic cells (DCs) are the most potent professional antigen-presenting cells with the unique ability of primary immune response initiation. DCs originate from bone marrow progenitors, which circulate in the peripheral blood and subsequently penetrate peripheral tissues, where they give rise to immature DCs. In peripheral tissues, DCs continuously monitor the microenvironment and, when the cells encounter 'danger' signals, DCs undergo differentiation and maturation. Maturing DCs usually migrate to lymphatic tissues, where they form contacts with $\mathrm{T}$ cells to initiate a primary immune response. DCs were identified in arteries in 1995 and since then, further knowledge has been gained about the peculiarities of vascular-associated DCs and their role in atherosclerosis. Immune reactions toward modified lipoproteins and other factors ignited by resident vascular DCs as well as by newly arrived DCs, which originate from blood monocytes, are believed to destabilize arterial homeostasis from very earlier stages of atherogenesis. There is a remarkable heterogeneity of DCs in atherosclerotic lesions. Some DCs mature and become capable of forming clusters with $T$ cells directly within the arterial wall. The predictive value of the numbers of circulating DC precursors in coronary artery disease and in atherosclerosis has been assessed, and it has been shown that DCs have a role in plaque destabilization. Over recent decades, DCs have proven to be a valuable instrument in immunotherapy approaches against cancer and various autoimmune diseases, and this explains the demand that the accumulated knowledge be applied to the field of atherosclerosis immunotherapy.

Laboratory Investigation (2010) 90, 970-984; doi:10.1038/labinvest.2010.94; published online 10 May 2010

KEYWORDS: dendritic cells; arteries; atherosclerosis; plaque destabilization

Antigen presentation is a key event in adaptive immune response. ${ }^{1}$ Until 1973, it was believed that macrophages and B cells were the only cell types capable of presenting antigens to T cells. ${ }^{1}$ The study by Steinman and Cohn, ${ }^{2}$ published in 1973, showed that another type of antigen-presenting cell exists with a powerful ability to initiate adaptive immune response. The newly identified cells were designated 'dendritic cells' (DCs). ${ }^{2}$ Since their first description, the role of DCs in immunity has been a focus of growing interest.

It is now well known that DCs are highly potent professional antigen-presenting cells responsible for capturing, processing and presenting antigen to $\mathrm{T}$ cells and thus, priming primary and secondary immune responses. ${ }^{3-6}$ DCs are sensors of both the innate and the adaptive arms of the immune system. ${ }^{3-10}$ As members of the innate immune system, DCs respond to molecules, which can be considered as 'danger' signals, by their prompt generation of protective cytokines. $^{3-10}$ As the key element of the adaptive immune system, DCs recognize and respond to dangerous molecules by eliciting the development of primary immune responses appropriate for the type of danger. ${ }^{3-10}$ DCs have a potent antigen-presenting capacity for the stimulation of naive, memory and effector T cells. ${ }^{3-10}$ DCs are responsible for activating not only conventional $\mathrm{T}$ cells but also natural killer $\mathrm{T}$ (NKT) cells. ${ }^{7-10}$ DCs are also involved in the maintenance of tolerance to antigens. ${ }^{3-10}$

During the development of adaptive immune responses, direct contacts are formed between DCs and T cells. ${ }^{3-10}$ In this interaction, $\mathrm{T}$ cells respond to peptide antigen displayed on major histocompatibility complex (MHC) class II and class I molecules present on DC surfaces. ${ }^{3-10}$ In DC/T-cell interactions, the presence of costimulatory molecules on DCs is crucial for T-cell activation and differentiation into effector cells. $^{3-10}$ In the absence of sufficient costimulation in DC/ T-cell interactions, $\mathrm{T}$ cells exhibit anergy or might even undergo apoptosis. $^{3-10}$ In DC/T-cell interactions, DCs secrete a spectrum of cytokines. ${ }^{3-11}$ The secretion or lack of secretion of interleukin (IL)-12, IL-23, IL-10 and other cytokines by DCs determines their ability to polarize naive $\mathrm{T}$ cells into Th1, Th2, T regulatory cells (Treg) or Th17 cells. ${ }^{3-11}$

Faculty of Medicine, SOMS, University of New South Wales, Kensington, NSW, Australia

Correspondence: Dr YV Bobryshev, PhD, Faculty of Medicine, SOMS, University of New South Wales, High Street, Kensington, NSW 2052, Australia.

E-mail: y.bobryshev@unsw.edu.au

Received 29 September 2009; revised 24 February 2010; accepted 8 March 2010 
The investigation of DCs in atherosclerosis represents a relatively new direction in DC research. The presence of DCs in nondiseased arteries was described for the first time in $1995,{ }^{12}$ and since then, knowledge has been gained that indicates the functional importance of DCs in atherogenesis. Different aspects of the participation of DCs in atherogenesis have been highlighted in a number of earlier reviews. ${ }^{13-24}$ This review briefly summarizes the current perception of the impact of DCs in atherogenesis, with special attention to the structural complexity of the population of vascular-associated DCs.

\section{FAMILY: ORIGIN AND MIGRATORY ROUTES DC Family: Origin}

According to the current paradigm, DCs originate from a common progenitor in the bone marrow. ${ }^{3-6}$ Their development involves three stages for which the terms 'precursors,' 'immature' and 'mature' are commonly used. ${ }^{3-6}$ Dramatic changes in the structural appearance and functional abilities of DCs during the transition through a precursor to immature then to mature stage sequence are striking and, perhaps, may be described as 'cell metamorphosis.' From a morphological point of view, the most striking feature of this 'metamorphosis' is that the structural appearance of immature DCs is more complex than that of mature DCs. DCs can be metaphorically described as wanderers which, during their life, change anatomical and tissue localizations, interacting during their migration with various other cell types. In different stages of their development and, accordingly, in different anatomical localizations, DCs fulfill different functions, which eventually allow them to reach a stage when they can activate or suppress $\mathrm{T}$ cells. ${ }^{3-6}$

In the first stage of their development, DC precursors leave the bone marrow to circulate through the bloodstream. The circulation time of DC precursors in the bloodstream varies, depending on targeted anatomical localizations. Circulating DCs are often termed 'blood DCs.' ${ }^{3-6}$

There are several pathways by which DC precursors can develop into immature DCs. ${ }^{8-10,17,18,20-24}$ Different types of DCs are believed to develop through different branches of hematopoietic pathways that involve different immediate precursor cells. $^{2-10,25-30}$ Different branches of hematopoietic pathways lead to the development of DCs with different functions. ${ }^{25-30}$ Depending on their origin and functional predisposition, there are several DC sub-populations, including myeloid DCs (mDCs) and plasmacytoid DCs (pDCs). ${ }^{25-30}$ Accumulating evidence indicates that mDCs are required for T-cell activation, whereas 'lymphoid' DCs (pDCs) induce T-cell tolerance. ${ }^{25-30} \mathrm{mDC}$ comprise subsets of 'conventional' DCs, including Langerhans cells and interstitial DCs, which express CD1c, CD11c and CD33 and secrete IL-12. ${ }^{25-30} \mathrm{pDCs}$ are characterized by the expression of CD123 (IL-3 receptor $\alpha$-chain) and are the most potent IFN- $\alpha$-producing cells in response to viral pathogens. ${ }^{25-30} \mathrm{In}$ contrast to mDCs, which display a 'typical' DC morphology relevant to their development stage, the appearance of pDCs is somewhat different. ${ }^{31}$ Freshly isolated human pDCs are round-shaped cells with short processes on their surfaces. ${ }^{31}$ At electron-microscopic examination, pDCs display the presence of eccentrically located nuclei and their cytoplasm contains a juxtanuclear Golgi apparatus and parallel arrays of cisterns of the endoplasmic reticulum. ${ }^{31}$ The ultrastructural appearance of pDCs somehow resembles the appearance of plasma cells, which led to their definition as 'plasmacytoid' DCs. ${ }^{31}$ However, there are obvious differences in the ultrastructural architectonics between pDCs and plasma cells. ${ }^{31}$ Incubation of pDCs with IL-3 and the CD40 ligand induces the formation of long cell processes and eventually, pDCs acquire the morphology of interdigitating cells. ${ }^{31}$ Apart from $\mathrm{mDC}$ and $\mathrm{pDC}$ sub-populations, blood monocytes have been shown to be able to acquire DC properties, and a subpopulation of DCs that do not display stellate shape has been designated as 'pre-DCs. ${ }^{30,32,33}$ Increased DC numbers appear at sites of inflammation where DCs display distinct profiles of surface receptors and are functionally unique. ${ }^{25-30}$ Inflammatory DCs have an important role in the induction of proinflammatory responses in situ at the sites of inflammation. ${ }^{25-30}$ It remains unclear whether inflammatory DCs represent a separate lineage to steady-state DCs or whether they develop from steady-state blood DCs upon arrival at the inflammation site. The development of different DC sub-populations is influenced by different combinations of cytokines and growth factors. ${ }^{3-10,25-30,32}$

The population of DCs in the body is highly heterogeneous. $^{2-10}$ Although many attempts to classify DC subpopulations have been made in the past few years, the complete model has not yet been established. DCs can be classified according to their anatomical location, morphological appearance, antigen expression, presumed origin, the T-cell response they initiate and their physiological/pathophysiological state ('steady-state DCs', 'inflammatory DCs'). ${ }^{3,25-28}$ In the steady state, the properties of DCs markedly vary according to the anatomical location. Steady-state DCs can be further divided into migratory or lymphoid tissue resident cells. Migratory DCs sample antigen in peripheral tissues before migrating through the lymph to lymphoid organs, whereas lymphoid tissue resident DCs are believed to arrive from the blood as precursors and develop in situ into DCs capable of activating T cells. ${ }^{25-28}$ Lymph nodes thus contain a mixture of both of these DC types. ${ }^{29}$

\section{Immature DCs: Morphology}

As soon as DC precursors reach and penetrate peripheral tissues, most of them take up residence at sites of potential entry of 'dangerous factors. ${ }^{3-6,34}$ Different monocyte populations can give a rise to DCs in tissues as well. ${ }^{32,33}$ DC precursors' penetration of peripheral tissues marks the second stage of their development, termed 'immature DCs.' In this stage, DCs can be identified in essentially all tissues, even though in any location, they represent only a minor cell type, 
Table 1 Distribution and histological nomenclature of dendritic cells (DCs) in normal tissues

\begin{tabular}{|c|c|c|c|}
\hline Cell type & Location & Major functional role & Distinctive structural feature(s) \\
\hline Blood dendritic cells & Peripheral blood & Migratory form of DCs & Nil \\
\hline Interstitial dendritic cells & & Antigen uptake/processing & Moderately developed tubulovesicular system \\
\hline Interdigitating dendritic cells & $\begin{array}{l}\text { Lymph node paracortex/splenic } \\
\text { periarteriolar lymphatic sheath }\end{array}$ & Antigen presentation & Well-developed tubulovesicular system \\
\hline Follicular dendritic cells & Germinal centers & Regulation of B-cell memory & Well-developed tubulovesicular system \\
\hline
\end{tabular}

usually constituting $<0.5-1 \%$ of the total cell population. In addition to the penetration of circulatory DCs into peripheral tissues, many 'individual tissues' may generate their 'own' DCs locally from reservoirs of immediate DC precursors, rather than depending on the continuous flux of DCs from the bone marrow. ${ }^{26}$

Immature DCs are predominantly concentrated along epithelial and body cavity surfaces, and are most frequently present in the skin as well as in the respiratory and digestive systems $^{3-6}$ (Table 1). In these locations, DCs continuously monitor the microenvironment by sampling and examining the extracellular content for the identification of dangerous signals. $^{3-6,34}$ From a morphological point of view, immature DCs are highly differentiated cells. In different locations, immature DCs display different structural features. The surface of immature DCs is characterized by the presence of long, thin cell processes, described as dendrites, as well as short veils. ${ }^{3-6}$ Some immature DCs contain unique cytoplasmic structures. Langerhans cells, described in 1868 as stellate cells in the epidermis of the skin, represent the most intensely studied example of the immature stage of migratory type DCs. ${ }^{3,35-41}$ Langerhans cells contain unique organelles, termed 'Birbeck granules,' which have the shape of a tennis racket or are rod-shaped structures with a central lamina consisting of bands of high electron density, regularly or intermittently interrupted by bands of low electron density. ${ }^{3,35-41}$ Birbeck granules contain specific molecules, termed 'Lag-antigen' and 'langerin' (CD207).,38,40-42 Other distinctive cytoplasmic structures of Langerhans cells include atypical dense granules and a tubulovesicular system, which represents modified and hypertrophied conglomerates of the smooth endoplasmic reticulum and complex Golgi. 3,36,39 Atypical dense granules resemble lysosomes but the presence of an electron-transparent oriole between the limiting external membrane and the electron-dense core allows distinguishing of these two organelles. ${ }^{3,39}$ Atypical granules can transform into Birbeck granules. ${ }^{3,39}$ Birbeck granules, atypical granules and the tubulovesicular system have been found to be involved in the recognition and processing of antigenrelated information collected from the surrounding extracellular space. ${ }^{3,40-42}$ The presence of Langerhans cells is not limited to the epidermis of the skin, and Langerhans-like cells can be identified in the gastrointestinal system, particularly in the esophagus. ${ }^{3}$ Other subtypes of immature DCs, distributed throughout peripheral tissues, are characterized by the presence of a tubulovesicular system and atypical granules, the structural transformations of which do not usually lead to the formation of Birbeck granules. Immature DCs in the lung are often termed 'lung DCs,' immature DCs in the liver are 'liver DCs,' in the heart they are 'heart DCs' and so on. ${ }^{3}$ Immature DCs, which lack Birbeck granules and are located in interstitial spaces in the majority of organs, are conventionally termed 'interstitial DCs. ${ }^{3}$

\section{Antigen Uptake by Immature DCs}

In peripheral tissues, immature DCs continuously monitor the microenvironment and efficiently evaluate the antigenic samples collected from the extracellular space by phagocytosis, by high-volume fluid-phase macropinocytosis, by receptor-mediated endocytosis, or by direct contact with necrotic, apoptotic or virally infected cells, and by other mechanisms. ${ }^{3-7,34,43-46}$ Internalized antigens are degraded into short peptides that are loaded onto nascent class I and class II MHC molecules for subsequent display on the cell surface. As DCs in their immature stage are not yet able to stimulate $\mathrm{T}$ cells, they are often termed 'processing' DCs. ${ }^{3,43-46}$ Processing DCs can also be described as 'activated DCs. ${ }^{3}$ In vivo, processing DCs usually exit the nonlymphoid tissues to migrate through the afferent lymph into the lymphoid regional lymph nodes. ${ }^{3-6,36}$

\section{Migration of Processing DCs in the Lymphoid Organs}

As soon as activated DCs enter the lymph, they undergo marked structural alterations, including a dramatic shrinkage of the tubulovesicular system and the disappearance of atypical and Birbeck granules; the cellular surface also 
changes with long dendrites being replaced by flapper-like cytoplasmic veils that are continuously extended and retracted. ${ }^{3,36}$ DCs in the afferent lymph are termed 'veiled cells. $^{.2-6,36}$ Structurally, veiled DCs appear as low-differentiated cells but they can be distinguished from lymphocytes by their more complex cell surface. ${ }^{3,36}$ It seems that, at present, it is impossible to establish from which peripheral tissue such veiled cells have arrived.

\section{Structural and Functional Alterations of Veiled DCs in the Lymphoid Organs}

Veiled DCs, having entered the lymph organs from the afferent lymph, progress to the last stage of their development, which provides the organism with mature DCs. ${ }^{3-6,36}$ In the lymphoid organs, veiled DCs transform into the so-called 'interdigitating cells' (or 'interdigitating DCs'). ${ }^{3,36}$ This transformation is accompanied by changes in the cell surface. Veils become replaced by long cellular processes (dendrites), and the tubulovesicular system undergoes remarkable hypertrophy. ${ }^{3,36}$ Accumulating evidence suggests that in interdigitating cells, the tubulovesicular system is involved in antigen processing and antigen presentation. ${ }^{3}$ By their appearance, interdigitating cells resemble interstitial DCs, but the tubulovesicular system in interdigitating cells is much more developed than in interstitial DCs. ${ }^{3}$ In the lymphoid organs, DCs complete their maturation process which involves the downregulation of endocytotic activity and the upregulation of adhesion molecules (CD11a, CD50, CD54 and CD58), costimulatory molecules (CD40, CD80/B7.1, CD86/B7.2) and antigen-presenting molecules, including the class I and class II of MHC proteins. ${ }^{2-10}$ The expression of the CD83 molecule, a member of the immunoglobulin superfamily, marks the complete maturation of DCs. ${ }^{3,7-10,47,48}$ Coexpression of adhesion, costimulatory and antigen-presenting molecules enables DCs to form contacts with, and to eventually activate, $\mathrm{T}$ cells. ${ }^{2-10}$ Despite the observation that the activation of $\mathrm{T}$ cells occurs predominantly in the lymphoid tissues, it is well appreciated that in at least some pathological conditions, the maturation of DCs can occur in the peripheral nonlymphoid tissues where DCs become capable of clustering with lymphocytes. ${ }^{2-10}$

\section{DCS AND ATHEROSCLEROSIS}

Structural Features and Heterogeneity of DCs in Human Atherosclerotic Arteries

Small numbers of DCs locate in the subendothelial layer of the intima of apparently normal, nondiseased human arteries. ${ }^{12,49-53}$ Since the first description of DCs in the arteries, ${ }^{12}$ knowledge has been gained that indicates the structural complexity of the population of vascular-associated DCs. Resident vascular-associated DCs have been designated 'vascular DCs' (VDCs). ${ }^{12}$ VDCs, recently described within the tertiary lymphoid structures in the aortic adventitia of the atherosclerotic vessels, might represent a unique sub-population of DCs. ${ }^{54}$
Notwithstanding the wide structural heterogeneity of cells in the DC family, they, including DCs, present in the arterial wall, exhibit distinct ultrastructural features, including a unique tubulovesicular system, which allows them to be unambiguously identified. ${ }^{3,12,36,39}$ The tubulovesicular system represents highly modified and hypertrophied conglomerates of complex Golgi and smooth endoplasmic reticulum. ${ }^{55}$

In the normal intima, structurally low-differentiated VDCs are predominantly present in close proximity to the endothelium (Figure 1a-c), whereas VDCs with a moderately developed tubulovesicular system are localized throughout the thickness of the tunica intima, mostly being concentrated in the subendothelial space (Figure 2a and b). By means of their long cellular processes, VDCs form multiple contacts between each other and with other cell types (Figures $3 a-c$ and $4 \mathrm{a}-\mathrm{e})$. In some processes, cisterns of the tubulovesicular system can be highly hypertrophied (Figure $3 \mathrm{a}-\mathrm{c}$ ), which could indicate that these DCs are activated. ${ }^{12,50}$

Ultrastructural investigations of the normal arterial intima and early atherosclerotic lesions have shown that, although the transitional stages between VDCs displaying different structural appearances can be found, the heterogeneous VDC

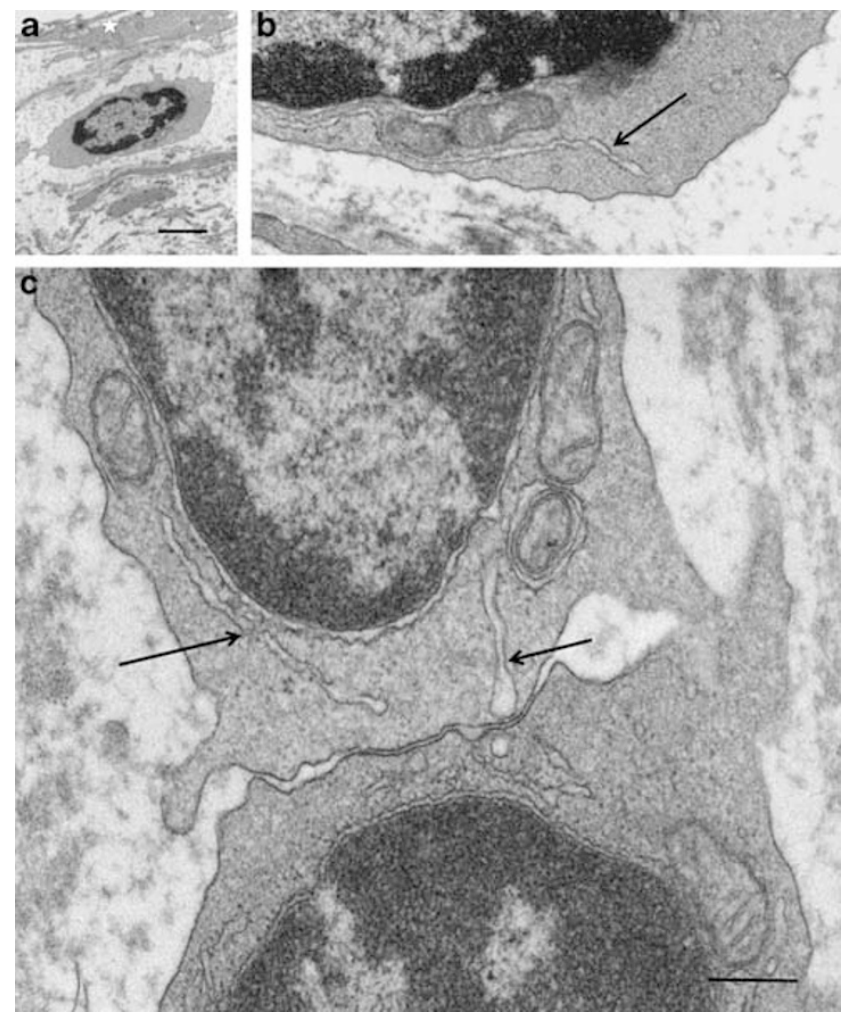

Figure 1 Low-differentiated cells showing signs of their differentiation into dendritic cells (DCs) in the subendothelial layer of the arterial intima (a-c). Panel b is a detail of panel a. In panel a, the star marks the endothelium. In panels $b$ and $c$, cisterns of the developing tubulovesicular system are marked by arrows. Human aorta. Electron microscopy (EM). Bars $=3 \mu \mathrm{m}$ (a), $1 \mu \mathrm{m}$ (c). 

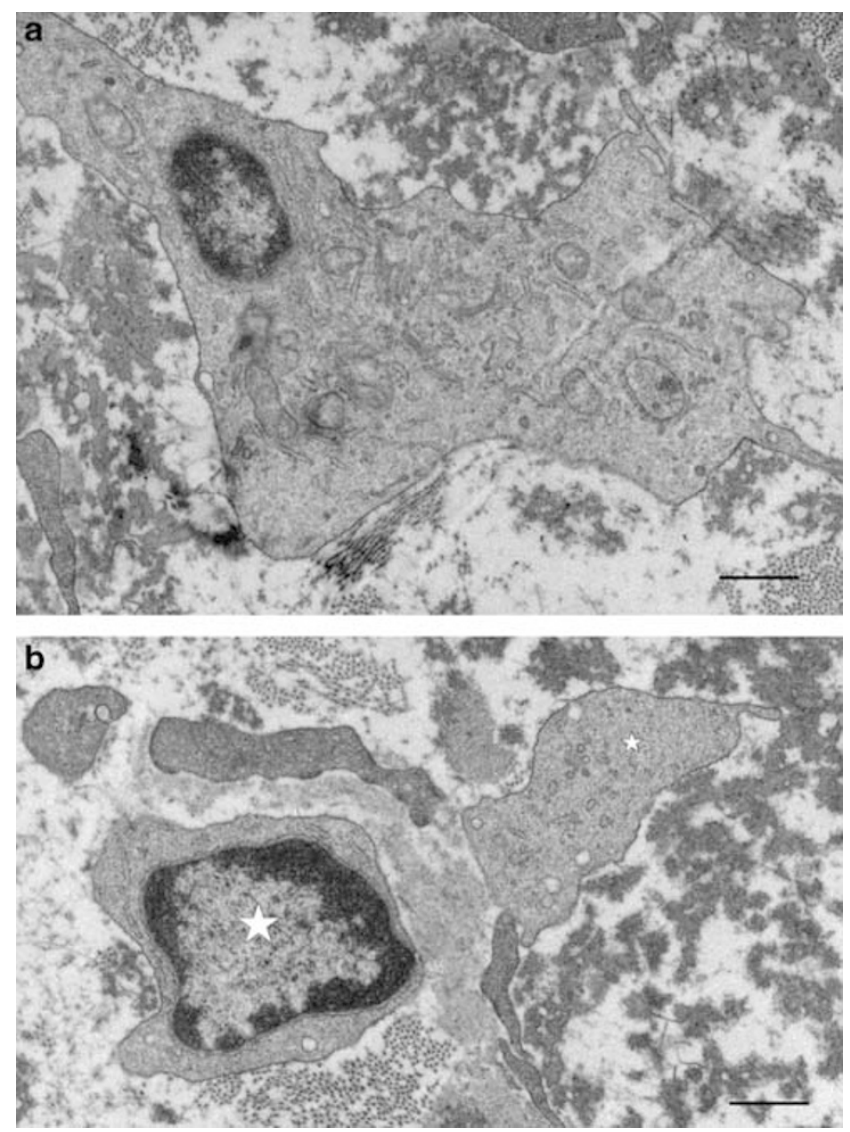

Figure 2 Typical appearance of DCs in the arterial intima $(\mathbf{a}, \mathbf{b})$. The tubulovesicular system is moderately developed, whereas the cytoplasm lacks lysosomes. (b) The continuity between the cell body (marked by the large star) and DC processes is not usually obvious in ultra-thin sections. The small star marks a DC process. Human aorta. EM. Bars $=2 \mu \mathrm{m}(\mathbf{a}, \mathbf{b})$.

population nevertheless falls into two main structural types: type I and type II VDCs (Figure 5a). ${ }^{56}$ The cytoplasm of type I VDCs is enriched with well-developed cisterns of the tubulovesicular system, but these cells lack lysosomes or other kinds of electron-dense granules (Figure $2 \mathrm{a}$ and $\mathrm{b}$ ). It might seem unusual that a cell could not have lysosomes, but it has been shown that DCs are capable of degrading antigens without the participation of lysosomes. ${ }^{44,45}$ DCs can bypass the antigen-internalization stage by the processing of antigens extracellularly and by loading antigenic peptides onto empty, surface class II MHC molecules. ${ }^{44,45}$ Perhaps, type I VDCs use this property. In contrast to type I VDCs, the cytoplasm of type II VDCs is characterized by the presence of a prominent number of atypical dense granules (Figure $5 \mathrm{~b}$ and c) ${ }^{56}$ which have been shown to represent precursors of Birbeck granules in Langerhans cells in the epidermis of the skin. ${ }^{3,37}$ However, in Birbeck granules in Langerhans cells, the central lamina is intermittent, whereas in Birbeck granulelike structures in type II VDCs, the central lamina is continuous (Figure $6 \mathrm{a}-\mathrm{c}$ ), which might indicate that type II VDCs represent a unique cell type within the DC family. ${ }^{57}$
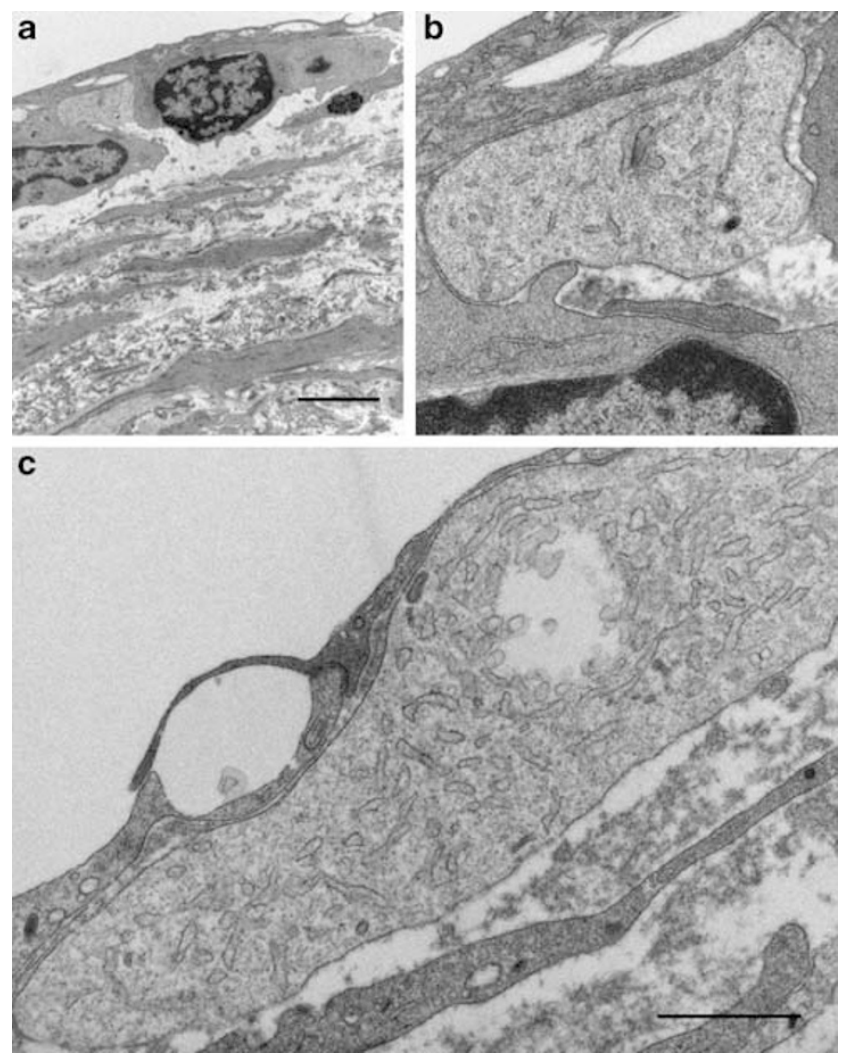

Figure 3 DC processes, containing hypertropically developed cisterns of the tubulovesicular system, are in direct contact with the luminal endothelium (a-c). In panel a, a DC process located within a cell cluster formed by lymphocytes. Panel b shows a detail of figure (a). Human aorta. $\mathrm{EM}$. Bars $=5 \mu \mathrm{m}$ (a), $1 \mu \mathrm{m}$ (c).

Another difference between Langerhans cells and type II VDCs can be revealed by immunohistochemistry using antiLag-antigen and anti-langerin antibodies: it has been shown that type II VDCs are immunopositive for Lag-antigen, ${ }^{57}$ but no langerin immunopositivity can be detected in the arterial wall. ${ }^{58}$ Both Lag-antigen and langerin are known to be present in Birbeck granules in Langerhans cells in the skin. ${ }^{3,37,39-42}$ Perhaps, the absence of the intermittence in the central lamina of Birbeck granule-like structures is associated with the lack of langerin in Birbeck granule-like structures in type II VDCs.

Although there are several other markers available for the identification of DCs in human arteries, such as S100, CD1a, CD1d, fascin, DC-LAMP and DC-SIGN, ${ }^{12,49-52,59-67}$ it is not yet known what portions of the total DC population in the arterial wall can be detected by these markers. It seems that S100 (S100A1 and S100B) is currently the most reliable marker for the visualization of at least the major portion of DC population in the human arterial intima (Figure $7 \mathrm{a}-\mathrm{c}$ ). Although S100 is not exclusively specific to DCs and it is expressed by neuronal cells, S100 specifically identifies DCs 

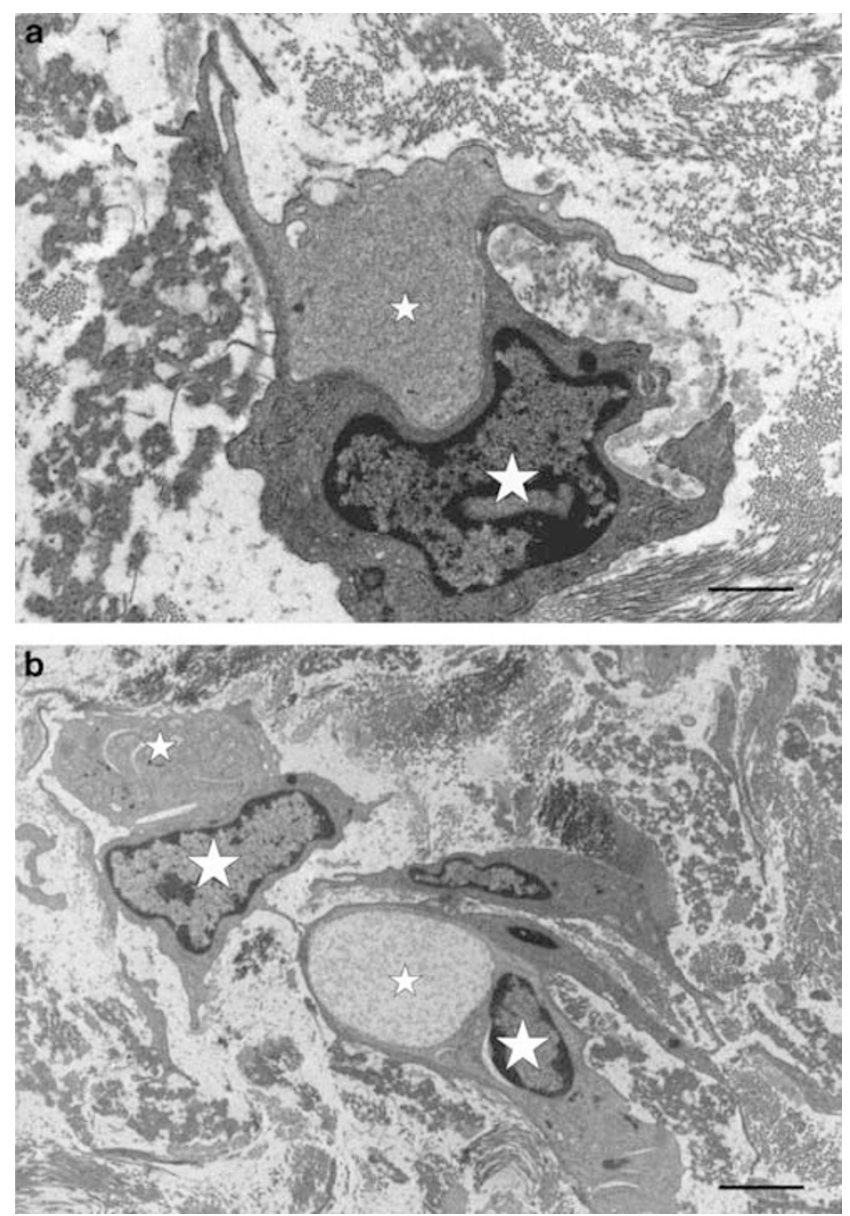

Figure 4 Complex associations between intimal cells (large stars) formed by DC processes (small stars) in early atherosclerotic lesions $(\mathbf{a}, \mathbf{b})$. Human aorta. EM. Bars $=1 \mu \mathrm{m}(\mathbf{a}, \mathbf{b})$.

in the arterial intima because the latter and two-thirds of the internal part of the tunica media are not innervated. ${ }^{49}$ Fascin $(55-\mathrm{kDa}$ actin bundling protein $\mathrm{p} 55)$ is also a suitable marker for identification of DCs. ${ }^{64,67}$ In contrast to the consistent expression of CD1a by Langerhans cells in the skin, ${ }^{3} \mathrm{CD} 1 \mathrm{a}$ is expressed only by a relatively small portion of the DC population in the arterial wall and the intensity of CD1a expression is markedly lower than that in the skin. Nevertheless, the presence of $\mathrm{CD} 1 \mathrm{a}+$ cells and networks formed by CD1a + DCs has been well demonstrated in a number of studies. ${ }^{51,52,60,61,63,68,69}$ Similarly, as it occurs with CD1a expression, only a small portion of DCs in the arterial wall express CD1b and CD1d. ${ }^{69,70}$ Molecules of the CD1 family are known to represent a large cluster of nonpolymorphic, MHC class-I-like molecules that bind distinct lipid-based antigens, which become recognizable by $\mathrm{T}$ cells. ${ }^{71,72}$ The most studied group of $\mathrm{T}$ cells that interact with lipid antigens is NKT cells, which characteristically express a semi-invariant T-cell receptor for CD1d recognition. ${ }^{72}$ Thus, CD1d can be used for the evaluation of the number of DCs, which has a potential to recognize lipid-based antigens in different types a
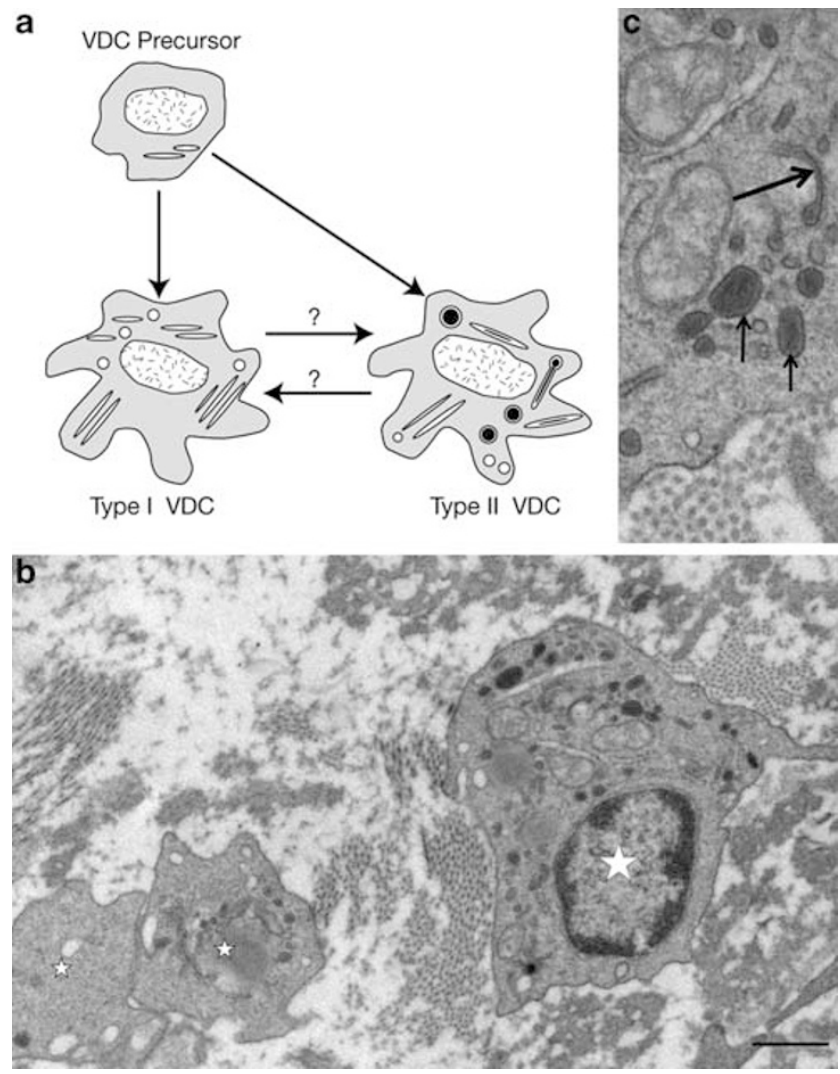

Figure 5 Phenotypic heterogeneity of DCs in the arterial intima (a-c). (a) Schema illustrating the structural features and possible relationship between the two phenotypes of vascular DCs (type I and type II VDCs). (b, c) DC, the cytoplasm of which contains atypical granules and Birbeck granule-like structures (type II VDCs). Panel $c$ is a detail of panel b. In panel $b$, the large star marks DC body, whereas DC processes are marked by small stars. In panel c, a Birbeck granule-like structure is shown by the large arrow, whereas small arrows show atypical dense granules. (b, c) Human aorta. EM. Bar $=5 \mu \mathrm{m}$ (b).

of atherosclerotic lesions. ${ }^{70,73,74} \mathrm{CD} 11 \mathrm{c}$, an integrin expressed preferentially by murine DCs, ${ }^{75-77}$ can be used for the identification of DCs in human arteries as well.

In addition to the usefulness of Lag-antigen for the identification of DC subtypes, ${ }^{57}$ the heterogeneity of DCs in the arterial intima can be shown by the application of BDCA-1 (CD303) and BDCA-2 (CD1c) antibodies, which identify myeloid and plasmacytoid types of DCs, respectively (Figure 8a and b). Immature and mature DCs can be distinguished by the use of anti-CD83, specifically expressed by mature DCs. ${ }^{47,48}$ In atherosclerotic lesions, CD83+ DCs often form clusters with $\mathrm{T}$ cells (Figure $8 \mathrm{c}$ and $\mathrm{d}$ ), which is in agreement with a speculation that direct activation of DCs might occur directly within the arterial wall. ${ }^{60} \mathrm{CD} 83+\mathrm{DCs}$ in atherosclerotic lesions express costimulatory molecules CD80 and CD86. ${ }^{61,62}$ The presence of mature DCs expressing CD83, CD80 and CD86 in atherosclerotic plaques has been shown not only by immunohistochemistry but also by quantitative PCR analysis. $^{62}$ 


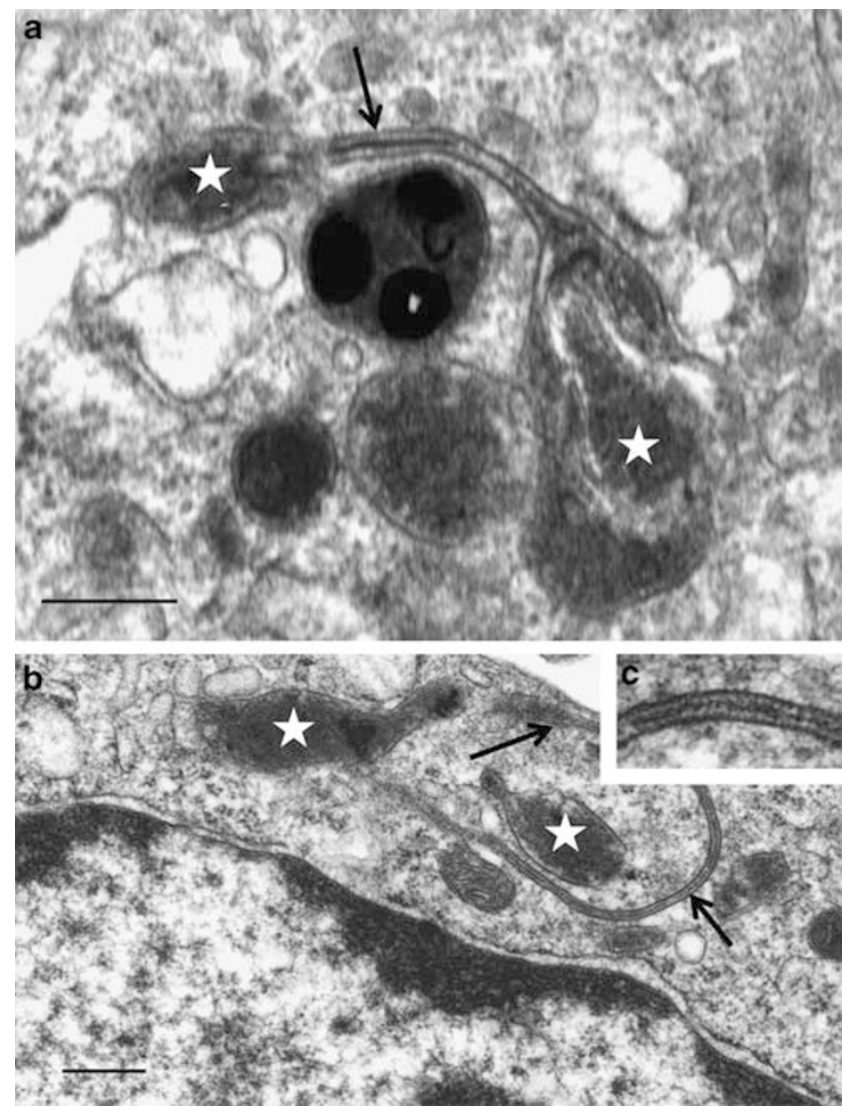

Figure 6 Transformation of atypical granules (stars) into Birbeck granulelike structures (arrows) in DCs in the arterial intima (a-c). Panel $\mathrm{c}$ is a detail of panel b. Human aorta. EM. Bars $=0.1 \mu \mathrm{m}$ (a), $0.2 \mu \mathrm{m}$ (b).

The population of DCs seems to become increasingly heterogeneous during the development of atherosclerotic lesions. ${ }^{60}$ In addition to intimal resident VDCs, blood monocytes migrate into the intima through the luminal endothelial cell monolayer and, depending on the microenvironmental conditions such as the content and composition of cytokines, ${ }^{78}$ may differentiate either into macrophages or into DCs. ${ }^{78,79}$ In some circumstances, even macrophages could become capable of dedifferentiation and acquisition of the DC phenotype. $^{80,81}$

Mapping of DCs in advanced atherosclerotic plaques shows that DCs are distributed highly irregularly throughout plaques. ${ }^{60}$ DCs are most frequently present in areas of neovascularization in the shoulders of plaques. ${ }^{60}$ Interestingly, not all foci of plaque neovascularization are associated with the presence of prominent numbers of lymphocytes, but all areas of neovascularization consistently contain DCs. ${ }^{60}$ One cannot exclude the fact that advanced atherosclerotic plaques receive new portions of DCs and DC precursors, invading plaques together with microvessels of neovascularization, which originate from adventitial vasa vasorum. This possibility is supported by observations of DCs in the adventitia of the normal arteries where DCs are predominantly located in close proximity to the capillaries of vasa vasorum on the
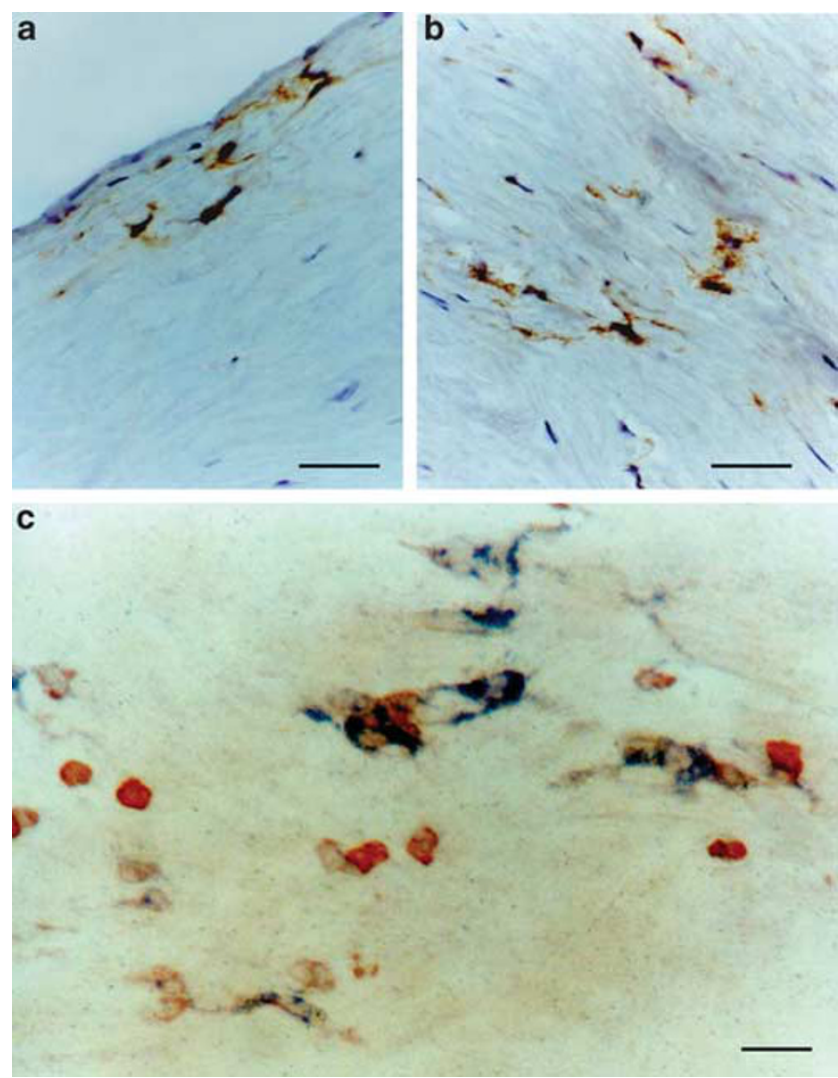

Figure 7 DCs in athero-predisposed areas of the human aorta (a-c). In panels $a$ and $b$, DCs were visualized using anti-S100 (Dako) in tissue specimens without signs of atherosclerosis. $A B C$ immunoperoxidase reaction; counterstaining with Mayer's hematoxylin. (c) Double immunostaining showing direct contacts between DCs (blue) and T cells (red) revealed in an en face-stained intimal sheet ('Hauthcen' specimen). S100 antigen was visualized with Fast Blue substrate, whereas visualization of CD3 antigen was produced with 3-amino, 9-ethylcarbazole (AEC) substrate. Bars $=25 \mu \mathrm{m}(\mathbf{a}-\mathbf{c})$.

media-adventitia junction. ${ }^{80,81}$ Ingrowths of vasa vasorum together with the lymphatics to advanced atherosclerotic plaques might facilitate the exchange of DC precursors and maturing DCs between the 'arterial tissue' and lymph. ${ }^{60} \mathrm{~A}$ scheme in Figure 9a depicts DC distribution in an atherosclerotic plaque and indicates their possible migratory routs. Neovascularization areas without prominent numbers of lymphocytes (NA) (Figure 9a and b; Table 2) might represent 'recent' ingrowths of adventitial vasa vasorum capillaries into the atherosclerotic intima. In neovascularization areas containing large numbers of lymphocytes (NA-II), frequent contacts between DCs and lymphocytes are common (Figure $9 a$ and c).

\section{Significance of DCs in the Maintenance and Breakdown of the Arterial Homeostasis: Theoretical Speculations and Experimental Insights}

In 1997, Wick et $a l^{82}$ postulated that VDCs have an important role in the maintenance of arterial homeostasis. 

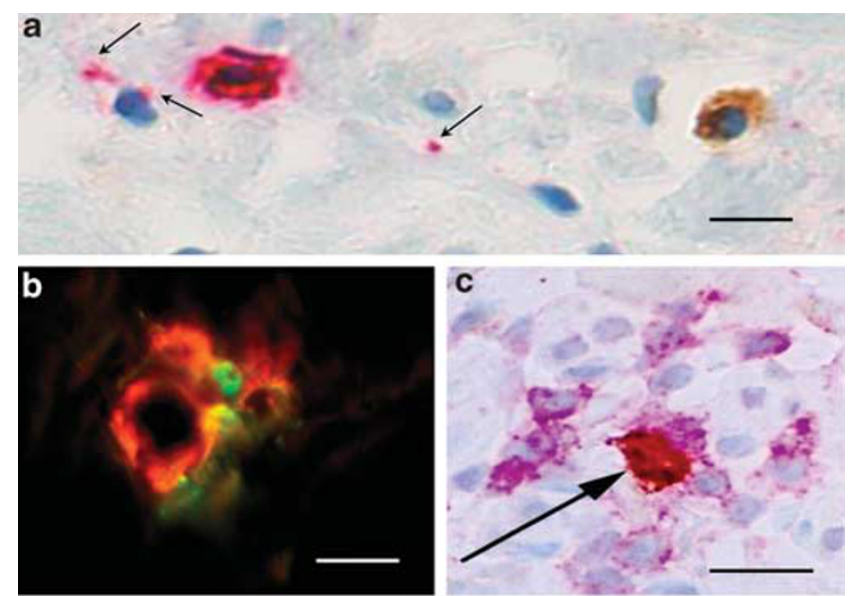

\section{d}

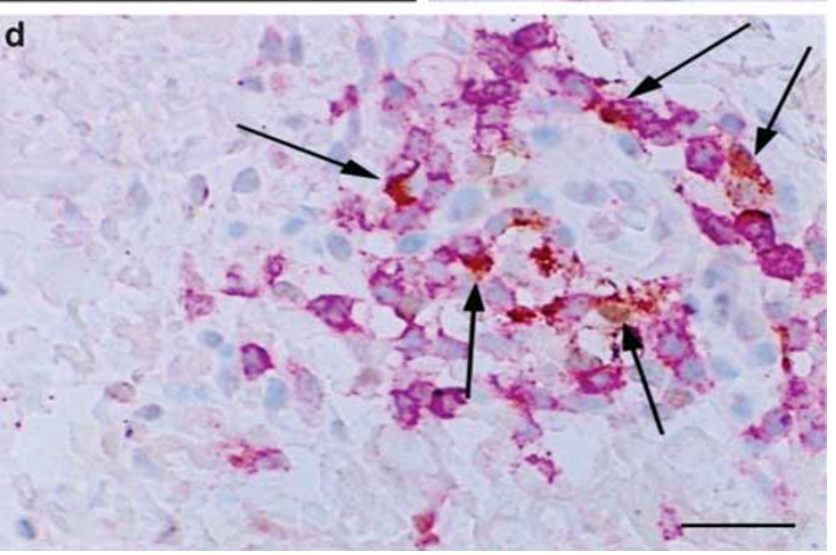

Figure 8 Different types of DCs and DC maturation in atherosclerotic lesions (a-d). (a) Double immunostaining showing the presence of both myeloid (rose) and plasmacytoid (brown) types of DCs in the arterial intima. Arrows show cross-sections of DC processes. BDCA-1 and BDCA-2 (Santa Cruz Biotechnology) were used for the identification of $\mathrm{mDCs}$ and $\mathrm{pDCs}$. Panel b shows close apposition of pDCs (BDCA-2+) (green) to endothelial cells (von Willebrand factor + ) (red) in an area of neovascularization in an advanced atherosclerotic plaque, revealed by immune fluorescent technique using a combination of RPE- or FITC-labeled secondary antibodies. (c, d) Clustering of mature DCs (brown) (arrows) with T lymphocytes (rose). Double immunostaining: DCs were identified with antiCD83 (PharMingen), whereas T cells were identified with anti-CD3 (Dako); combination of $A B C$ immunoperoxidase reaction (brown reaction product) and Fast Red substrate kit (rose reaction product); counterstaining with Mayer's hematoxylin. Human aorta specimens. Bars $=25 \mu \mathrm{m}(\mathbf{a}), 75 \mu \mathrm{m}$ (b), $40 \mu \mathrm{m}$ (c, d).

Wick et al and colleagues have developed a concept of vascular-associated lymphoid tissue (VALT), which is analogous to the mucosa-associated lymphoid tissue of the respiratory and gastrointestinal tracts. ${ }^{58,82}$ VALT consists of a small number of VDCs, $\mathrm{T}$ cells and resident macrophages distributed throughout the subendothelial layer of the arterial intima along the luminal endothelial monolayer. ${ }^{51,52,58,82}$ VDCs represent the key element, integrating other cell types within VALT into focal cellular networks and screen 'vascular tissue' for potentially harmful antigens. ${ }^{58,82}$ The existence of such cellular networks has been demonstrated by ultrastructural and immunohistochemical examinations of

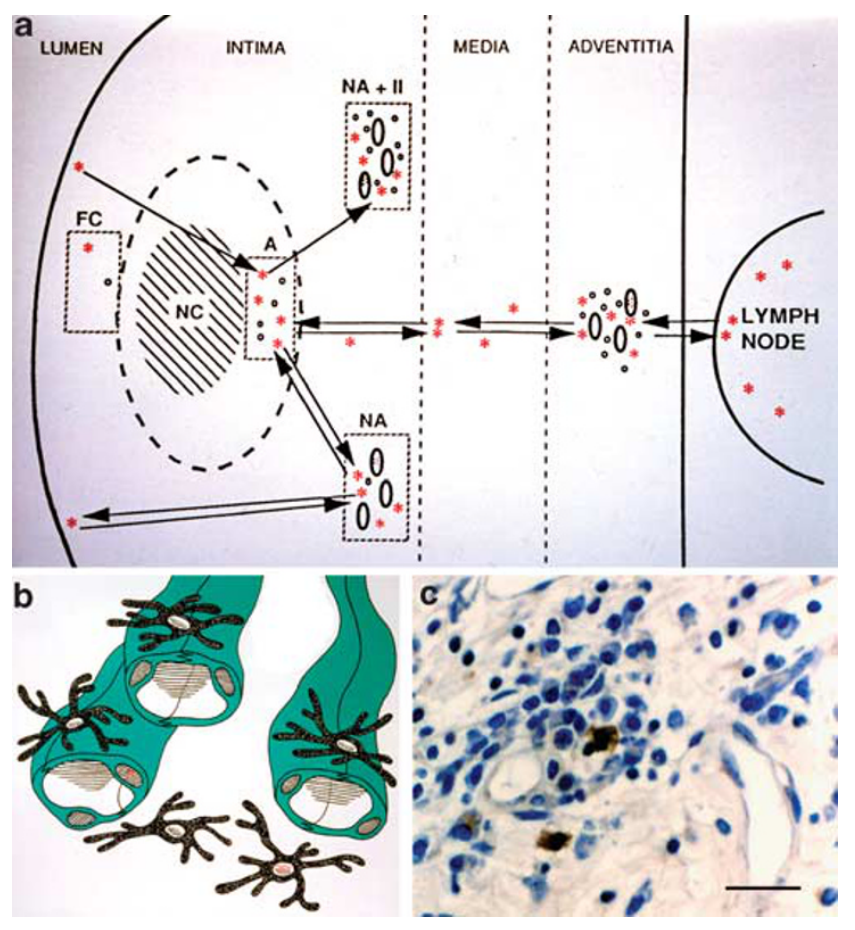

Figure 9 Distribution of DCs in atherosclerotic plaque (a-c). (a) Scheme of DC distribution in an atherosclerotic plaque and their possible migration (explanation in text). Red asterisks $\left(^{*}\right)$ indicate DCs; small black circles (o) indicate $T$ cells; ellipse indicates capillary from the neovascularization plexus in the plaque and capillary of vasa vasorum in the adventitia. FC-fibrous cap; NA + II-neovascularization area associated with prominent inflammatory infiltrates; NA-neovascularization area not associated with signs of inflammation; A-an ārea without neovasscularization surrounding the necrotic core; NC-the necrotic core. Arrows indicate the possible DC migration routes. (b) Scheme illustrating association of DCs (black) with capillaries in areas of plaque neovascularization. (c) DCs in an area of neovascularization enriched by immune-inflammatory cells (NA + II). DCs were visualized using anti-fascin (Dako). ABC immunoperoxidase reaction; Counterstaining with Mayer's hematoxylin. Bar $=40 \mu \mathrm{m}$.

Table 2 Frequency of immune-inflammatory cells in different areas of complicated atherosclerotic plaque (cells per vision field, $10 \times \mathbf{4 0}$ magnification; see Figure 9a)

Cell type Area subdivision

\begin{tabular}{lcccc} 
& FC & NA+ll & NA & A \\
\cline { 2 - 5 } & + & $++/+++$ & $++/+++$ & \pm \\
DCs & + & +++ & + & \pm \\
T-cells & + & + & + & $++/++$
\end{tabular}

$\mathrm{FC}$, fibrous cap; NA+Il, neovascularization areas associated with massive inflammatory infiltrates; NA, neovascularization areas not associated with signs of inflammation; $A$, areas surrounding the necrotic core.

Semi-quantitative graduating scale $(-$ to +++$)$ for estimating cell numbers:

For dendritic cells (DCs): - indicates that no cells were detected; + indicates 1-2 cells; ++ indicates $2-5$ cells; +++ indicates $>5$ cells.

For $T$ cells and macrophages: - means cell number $<2 \%$ of the total cell population; + <20\%; ++ 50\%; +++ $>50 \%$. 
human large arteries, including the aorta, carotid and coronary arteries. ${ }^{12,58,60,82}$ In the arterial wall, VDCs may have a role in not only the surveillance but also in the tolerization against autoantigens by silencing T-cell responses, just as this occurs in other anatomical locations. ${ }^{83,84}$

Assessment of the numbers of VDCs in the intima of atherosclerosis-prone and atherosclerosis-resistant areas of the nondiseased human aorta has found that, in atherosclerosis-prone areas, there were more VDCs than in atherosclerosis-resistant areas. ${ }^{12}$ In atherosclerosis-prone areas, VDCs were found to form cell clusters. ${ }^{85}$ The increased numbers of VDCs have also been identified in the intima of the carotid arteries of children, 8 weeks to 10 years of age, at sites subjected to major hemodynamic stress and predisposed to the development of atherosclerosis. ${ }^{68}$ The accumulation of clustering DCs in other pathological conditions has been reported to be an earlier indicator of the development of autoimmune disease. ${ }^{3}$

According to the autoimmune hypothesis of atherosclerosis proposed by Wick et al, ${ }^{58,82}$ VALT activation by autoantigens is responsible for the initiation of immune responses in the arterial wall, which eventually lead to atherosclerotic alteration. Modification of various molecules and lipoproteins, as well as molecular mimicry may lead to the recognition of self-determinants by VDCs. The observations of VDCs, accumulating and clustering in atherosclerosisprone areas of arteries, ${ }^{12,85}$ are supportive of the concept that immune mechanisms are involved in the formation of atherosclerotic lesions from the very early stages of the disease. $^{13,16,58,82}$

The identification of DCs in the arteries of animal models ${ }^{86-88}$ has facilitated the investigation of the impact of DCs in atherosclerosis. Necropsy observations and theoretical speculations ${ }^{12,49,50,58,82}$ have received support from experimental animal studies, which focused on the elucidation of the functional significance of DCs in atherogenesis. ${ }^{75,76,89-93}$ Ludewig et $a l^{94}$ were the first to report a link between immune-mediated arterial inflammation and cholesterol-induced atherosclerosis in a transgenic mouse model, mediated by DCs. Angeli et a $l^{95}$ demonstrated that dyslipidemia associated with atherosclerotic disease systemically alters the DC function. Despite that oxidized low-density lipoproteins (oxLDLs) could be potentially dangerous for the survival of DCs, a study by Packard et al ${ }^{96}$ showed that DCs can maintain antigen-processing and antigen-presenting capabilities, which allow them to efficiently prime $\mathrm{T}$ cells under hypercholesterolemic conditions associated with atherosclerosis. An experimental study by Liu et $a l^{97}$ demonstrated that DC accumulation in arterial lesions is associated with plaque growth and inflammation. Further understanding of the impact of DCs in atherosclerosis has been achieved in a recent study by Gautier et al. ${ }^{77}$ Gautier et al ${ }^{77}$ have created a mouse model in which the lifespan and immunogenicity of DCs were enhanced by specific overexpression of the antiapoptotic gene hBcl-2 under the control of the CD11c promoter. In either LDL receptor-deficient or apolipoprotein E-deficient backgrounds, DC-hBcl2 mice exhibited an expanded DC population associated with enhanced T-cell activation, a Th1 and Th17 cytokine expression profile, as well as elevated production of Th1-driven IgG2c autoantibodies directed against oxidation-specific epitopes. ${ }^{77}$ However, this proatherogenic signature was not associated with the acceleration of atherosclerotic plaque progression because expansion of the DC population was unexpectedly associated with an atheroprotective decrease in plasma cholesterol levels. ${ }^{77}$ Conversely, a depletion of DCs in hyperlipidemic CD11c-diphtheria toxin receptor/apolipoprotein E-deficient transgenic mice resulted in enhanced cholesterolemia, thereby arguing for a close relationship between the DC population and plasma cholesterol levels. ${ }^{77}$ These experiments have convincingly demonstrated that DCs are central to the atherosclerotic process because they are directly implicated in both cholesterol homeostasis and immune response. $^{77}$

Recent experiments using DCs for vaccination in mouse models of atherosclerosis confirmed that DCs are functionally significant in atherogenesis. ${ }^{98-100}$ Vaccination using mature DCs pulsed with oxLDL-induced oxLDL-specific T cells with a lowered Th1 response, increased the levels of oxLDLspecific antibodies and reduced lesion size. ${ }^{98}$ Hjerpe et al ${ }^{99}$ have reported that DCs pulsed with malondialdehyde modified LDL aggravate atherosclerosis in ApoE $(-/-)$ mice.

\section{Tissue Microenvironment in Atherosclerosis and DC Function}

The number of DCs increases in the early development of atherosclerotic lesions. ${ }^{49}$ This might occur as a result of either the induction of intensified differentiation of silent VDC precursors that preexist in the subendothelial layer, possibly from embryonic stages, or alternatively, as a result of the migration of monocytes and other DC precursors into the intima from the bloodstream. ${ }^{60,78,79}$ In the second scenario, the interaction of DC precursors with the luminal endothelium is of special importance. ${ }^{101}$

Chemotactic stimuli and the involvement of adhesion molecules are necessary for the invasion of DCs into the intima. ${ }^{101}$ Chemokines, such as CCL2, CCL5 and fractalkine, and adhesion molecules such as P-selectin, E-selectin and vascular cell adhesion molecule-1 (VCAM-1) are implemental in the accumulation of DCs in the arterial intima. ${ }^{17,20,21,24,101}$ CX3CR1 deficiency has been shown to impair DC accumulation in the arterial wall in a mouse model. ${ }^{97}$ Under in vitro conditions, DC adhesion and migration through the endothelium are modulated by changes in endothelial function. ${ }^{101,102}$ DC adhesion and transmigration are markedly increased after exposing endothelial cells to hypoxia and TNF- $\alpha$, known as stimuli that accelerate atherogenesis. ${ }^{101,102}$ The inhibition of endothelial NO synthase increased DC binding and transmigration, whereas the augmentation of endothelial NO synthase activity has been 
found to prevent DC adhesion. ${ }^{101}$ Increased adhesion of DCs to endothelial cells in vitro is promoted by oxLDL. ${ }^{101}$

In the arterial intima, immature DCs can be activated by various stimuli. ${ }^{101-106}$ Cellular components, released from dying cells, collectively called damage-associated molecular patterns and pathogen-associated molecular patterns that originate from microbes and viruses can induce the activation and maturation of DCs. ${ }^{7-9}$ Ultrastructural analysis of the nondiseased intima of athero-prone areas of the aorta has shown that in this location, there is a casual presence of dying cells and cells exhibiting signs of destruction. ${ }^{12}$ Cellular debris is a typical feature of intimal thickenings. ${ }^{107}$

Atherosclerotic plaques contain a large number of necrotic cells. ${ }^{108,109}$ Viruses and microbes can be identified in some atherosclerotic lesions, ${ }^{110,111}$ with components of Chlamydia pneumoniae being detectable in the cytoplasm of DCs. ${ }^{112}$ DCs receive signals through various pattern-recognition receptors, including Toll-like receptors (TLRs), cell-surface C-type lectin receptors and intracytoplasmic NOD-like receptors. ${ }^{7-9}$ DCs sense the lipid environment by nuclear hormone receptors, such as peroxisome proliferator-activated receptors (PPARs), liver X receptors (LXRs) and others. ${ }^{113,114}$ The most investigated receptors for recognizing signals are TLRs. ${ }^{15,115,116}$ TLR4 which has a central role in the initiation and progression of atherosclerosis is expressed by DCs in the arterial wall. ${ }^{117,118}$ Modified autoantigens, such as oxLDL, heat-shock proteins (HSPs) and fragments of bacteria, such as lipopolysaccharides, are recognized by TLR4, followed by the activation of the subsequent signaling cascade. ${ }^{15,117-123}$ TLR2 may contribute to atherogenesis, possibly activating DCs due to the presence of Chlamydia pneumoniae in atherosclerotic lesions. ${ }^{122}$ TLR7, TLR8 and TLR9, which recognize motifs of nucleic acids deriving from infectious pathogens and from dying cells, may also be involved in DC activation. ${ }^{115,116,121}$ It has been suggested that vessel-specific TLR expression patterns can induce distinct types of vascular inflammation as result of selective susceptibility of different regions of the vascular tree to atherosclerosis. ${ }^{121}$

Antigens, such as oxLDL and HSPs, bind to TLRs and to scavenger receptors. ${ }^{13,15,115,123,124}$ The formation of oxLDL and otherwise modified LDL and their accumulation in the arterial intima are key events in atherosclerosis. ${ }^{108}$ From the very early stages of atherosclerotic alteration, the arterial intima represents a vicinity of increased coaccumulation of oxLDL and DCs. ${ }^{13,83}$ DC function has been shown to be affected by oxLDL and otherwise modified LDL. ${ }^{124-126}$ Nickel et $a l^{124}$ have reported that DCs are capable of the uptake of LDL in vitro and that the pronounced oxLDL uptake capacity is associated with the expression of LOX1, CD36 and CD205 molecules on the DC surface. ${ }^{124}$ Similarly, this occurs with macrophages wherein LOX-1, CD36 and CD205 act as scavenger receptors for DCs. ${ }^{124}$ However, in contrast to macrophages, the vast majority of DCs in atherosclerotic lesions do not transform into foam cells. ${ }^{127}$ The understanding of DC protective mechanisms against excessive lipid accumu- lation may be instrumental in the development of approaches for the suppression of foam cell formation in atherosclerosis.

Oxidized LDLs promote mature DC transition from monocytes and induce prominent DC clustering. ${ }^{125,126}$ The interaction of DCs with oxLDL leads to DC maturation, triggered, at least in part, by activation of the $\mathrm{NF} \kappa \mathrm{B}$-pathway. ${ }^{124}$ This interaction also induces a proinflammatory cytokine profile in DCs. The production of pro-atherogenic cytokines IL- 6 and IL-13 occurs, whereas the release of antiatherogenic IL-10 is reduced. ${ }^{124}$ DC-derived IL-13 appears to be one of the critical factors for DCs to acquire the capability to induce Th2 cytokine production. ${ }^{124}$ Mature oxLDL-presenting DCs are essential for priming naive $\mathrm{T}$ cells that induce the formation of subsets of oxLDL-specific T cells. ${ }^{124}$ The ability of oxLDL to induce CD83 upregulation in vitro ${ }^{124}$ may explain that up to $70 \%$ of DCs in some foci of atherosclerotic plaques are mature and capable of clustering with T cells. ${ }^{61}$

During the last few years, the mechanisms and factors affecting the differentiation and maturation of DCs have been intensely studied in both in vitro and in vivo experimental settings, relevant to atherosclerosis. ${ }^{128-138}$ It has been shown that Apolipoprotein A-I, the major protein component of serum high-density lipoproteins, inhibits DC differentiation and maturation. ${ }^{132}$ PPAR- $\alpha$ agonists ciglitazone and fenofibrate also inhibit oxLDL-induced maturation and immune functions of DCs in vitro. ${ }^{133,134}$ Advanced glycosylation end products can promote atherosclerosis by inducing maturation of DCs. ${ }^{135}$ In advanced atherosclerotic plaques, especially in areas around the lipid cores which lack neovascularization, DC function can be affected by hypoxia. ${ }^{136-138}$

In atherosclerotic lesions, activated DCs display an abundance of HSP-70, indicating that the activation of DCs might be linked to cell stress. ${ }^{139}$ Upon activation, DCs produce mediators of the innate immune system and undergo a maturation process which involves the expression of costimulatory molecules such as CD80 and CD86, which are crucial for the induction of adaptive immune responses. ${ }^{3-10}$ Mapping of the distribution of DCs in atherosclerotic lesions has shown that DCs are most frequently present in areas enriched with $\mathrm{T}$ cells ${ }^{60}$ and, particularly so, within inflammatory infiltrates where DCs are found to cluster with $\mathrm{T}$ cells (Figures $7 \mathrm{c}$ and $8 \mathrm{c}, \mathrm{d}$ ). CD83 + DCs in plaques produce the T cell-attracting chemokines CCL19 and CCL21. ${ }^{140}$ DCs clustering with $\mathrm{T}$ cells display the intercellular cell adhesion molecule- 1 and VCAM- $1,{ }^{60}$ interactions of which with leukocyte function-associated antigen- 1 and very late activation antigen-4, respectively, are essential for T-cell activation. ${ }^{141}$ In DC/T-cell interactions, DCs display CD $40^{60,142}$ and express high levels of HLA-DR ${ }^{60}$ and CD1 molecules. ${ }^{60,73,74}$

An experimental in vivo study has shown that trafficking of monocyte-derived DCs from atherosclerotic plaques occurs during lesion regression, but little DC emigration has been detected from progressive plaques, suggesting that the progression of atherosclerotic plaques may result not only from 
the robust monocyte recruitment into arterial walls but also from the reduced emigration of DCs from lesions. ${ }^{143}$ This finding is in agreement with studies of human arterial tissue, which have indicated that only some DCs may migrate to the lymph nodes, whereas other DCs may activate $\mathrm{T}$ cells directly within the intima. ${ }^{60}$ The fact that successful antigen presentation might occur directly within the arterial wall is supported by the identification of clonally expanded $\mathrm{T}$ cells in atherosclerotic plaques. ${ }^{144}$ Isolated VDCs have been reported to be capable of presenting antigen to transgenic $\mathrm{T}$ cells as effectively as bone marrow-derived mDCs. ${ }^{20}$ It is believed that the migratory routes of other activated DCs, which avoid contacts with $\mathrm{T}$ cells within plague, might be similar to the migratory routes known for Langerhans cells of the skin. ${ }^{60}$ After engulfing antigen in the arterial wall, DCs might migrate as veiled cells through the afferent lymph into regional lymph nodes where they fulfill their antigenpresenting function. Supporting this possibility are immunohistochemical observations which have shown that the number of interdigitating cells in para-aortic and jugulodigastric lymph nodes attached to atherosclerotic arterial wall segments exceed those in the lymph nodes attached to nonatherosclerotic arterial segments. ${ }^{60}$ DCs might migrate from the intima to the adventitia and thence to lymph nodes, but it cannot be excluded that can also be an exchange of DCs back and forth between the arterial wall and lymph nodes (Figure 9a). It has also been suggested that some DCs could emigrate to the blood stream. ${ }^{16,143}$

Apart from the formation of direct contacts with $\mathrm{T}$ cells (Figures $7 \mathrm{c}$ and $8 \mathrm{c}, \mathrm{d}$ ), DCs in atherosclerotic lesions have been found to have direct contacts with B cells $(\mathrm{CD} 20+)$, and this immunohistochemical finding has been confirmed by electron-microscopic observations. ${ }^{145}$ Follicular DCs (FDCs) are known as cells that facilitate antigen recognition by B cells in follicles in lymphoid organs. ${ }^{3}$ This kind of DC is not bone marrow derived and is purely a resident of the follicles of secondary lymphoid organs. ${ }^{3}$ In atherosclerotic lesions, no expression of markers specific to FDCs has been detected which allows speculation that atherosclerotic lesions contain an unusual subset of DCs capable of forming contacts with B cells and plasma cells. ${ }^{145}$

The significance of this DC subset in the eliciting of antibody production requires investigation. Interestingly, complement component $\mathrm{Clq}$, which is expressed by interdigitating cells and FDCs in the spleen, and which is believed to be involved in capturing immune complexes, ${ }^{146,147}$ is also expressed by some DCs in atherosclerotic lesions. ${ }^{148}$

\section{Impact of DCs on Plaque Destabilization}

In atherosclerotic plaques, the number of DCs increases with most DCs accumulating in plaque shoulders, which represent plaque rupture-prone regions. ${ }^{60,61}$ Yilmaz et al ${ }^{61}$ have found that up to $70 \%$ of DCs in the shoulders of vulnerable carotid plaques express markers of DC activation, such as CD83 and DC-LAMP. In plaque rupture-prone regions, activated DCs were found to form direct contacts with T cells. ${ }^{60,61}$ Apart from conventional T cells, NKT cells have been found to form T-cell/DC contacts. ${ }^{73}$ Cell clusters, consisting of activated DCs and T cells, are associated with plaque destabilization. ${ }^{60,61,140}$ Enhanced recruitment of immune cells through neovessels into plaque shoulders has been linked to the high expression of chemokines/chemokine receptors. ${ }^{140}$

It has been reported that DC numbers in plaques are markedly elevated in patients with acute ischemic symptoms. ${ }^{61}$ In statin-treated patients, atherosclerotic plaques contain significantly lower numbers of DCs than plaques in patients without statin treatment. ${ }^{61}$ The beneficial effects of statins in atherosclerosis might be explained by the inhibition of the maturation process and antigen-presenting function of DCs, as shown in in vitro experiments. ${ }^{149-151}$ The numbers of circulating DC precursors in coronary artery disease (CAD) and in patients with cerebrovascular disease (CVD) are of increasing interest. ${ }^{152-154}$ The numbers of mDCs and pDCs have been assessed in a number of studies, and the results are indicative of the clinical importance of evaluating the predictive values of the number of different DC types in CAD and CVD. ${ }^{152,154}$ It has been shown that patients with stable CAD have lower levels of circulating DC precursors than do healthy individuals. ${ }^{152,154}$ This decrease seems to be an independent predictor of the presence of, and subsequent therapeutic procedure in, stable CAD. ${ }^{152,154}$ In patients with $\mathrm{CAD}$ and patients with unstable angina pectoris, DC function is altered. ${ }^{152-157}$

\section{DCs as a Possible Instrument in Atherosclerosis Immunotherapy}

It may be quite some time before vaccination trials for atherosclerosis can begin. ${ }^{158,159}$ Perhaps, DCs might be used for vaccination in atherosclerosis. ${ }^{160}$ As DCs not only activate $\mathrm{T}$ cells but also tolerize $\mathrm{T}$ cells to antigens that are innate to the body (self-antigens), ${ }^{3-10}$ it may be possible to engage DCs in the disarming of damaging immune responses in atherosclerosis. ${ }^{160}$ This might be achieved by either using different types of 'natural' DCs or by producing in vitro 'synthetic' DCs with desirable properties. ${ }^{160}$ In atherosclerosis immunotherapy, DCs could be used for the regulation of Th1/ Th2 balance or Th17 response. DCs might be exploited to expand CD4 + Foxp3 + Treg cells. Therapeutic intervention in atherosclerosis might also involve the direct targeting of DCs in vivo and may include manipulating the functions of myeloid and lymphoid subsets of DCs. ${ }^{160}$ Approaches using DCs in atherosclerosis immunotherapy might be similar to or different from those already used for cancer immunotherapy. ${ }^{3,161-166}$

It has been reported that immunization with oxLDL or with specific epitopes of the apolipoprotein B-100 component of LDL represents a promising therapeutic approach against atherosclerosis. ${ }^{167-169}$ Perhaps, oxLDL-pulsed DCs or DCs pulsed with components of LDL could be used for vaccination as well, using approaches developed for cancer 
immunotherapy. One of the approaches currently used in cancer immunotherapy is based on a technique, in which DCs are isolated from the peripheral blood and pulsed ex vivo with the appropriate antigen before being used for vaccination. ${ }^{3,161,162}$ Perhaps, vaccination with oxLDL-pulsed DCs in such a manner might avoid the side effects of direct vaccination with oxLDL. For purposes of the vaccination, DCs can be pulsed not only with oxLDL. DCs obtained from the peripheral blood can be pulsed ex vivo by cultivating them with a total extract or suspension of atherosclerotic plaque tissue, obtained, for example, from patients undergoing carotid endarterectomy. ${ }^{160}$ Vaccination of a person with their 'own' DCs, pulsed by their 'own' antigens, might tend to be more suitable and efficient due to the existence of individual peculiarities in the development of atherosclerosis. ${ }^{160}$ The incubation of 'own' DCs with 'own' danger factors ex vivo would imitate events as they occur in plaques in situ in a patient. As the presentation of antigen complexes to $T$ cells in the absence of costimulatory signals could lead to the anergy and apoptosis of $\mathrm{T}$ cells, the expression of costimulatory molecules on pulsed DCs can be adjusted, as desired, ex vivo before vaccination. Remarkable achievements in the development of techniques for the ligation of costimulatory molecules have made it possible to generate DCs with desirable properties. ${ }^{3,161-166}$ Recent experimental studies, using DCs for vaccination in mouse models of atherosclerosis, support a possibility that DCs might represent a valuable instrument in atherosclerosis immunotherapy. ${ }^{98-100}$

\section{CONCLUDING REMARKS}

Atherosclerosis is a chronic immune-inflammatory disease. Atherosclerotic plaques contain inflammatory infiltrates consisting of activated T cells. Antigen-specific T-cell activation depends on the interactions of $\mathrm{T}$-cell receptors with antigens presented by MHC and CD1 molecules by DCs. DCs have critical antigen-presenting and antigen-priming roles in the initiation of atherosclerosis. Various signals that promote the activation of DCs drive the maturation of DCs to prime self-specific responses and drive the perpetuation of vascular inflammation. These signals include, in particular, oxLDL and infection. Some DCs undergo maturation and cluster with $\mathrm{T}$ cells and $\mathrm{B}$ cells directly within atherosclerotic lesions, whereas others migrate to lymphoid organs. There now exists a rising demand to exploit the properties of DCs in addressing the need for atherosclerosis immunotherapy.

\section{ACKNOWLEDGEMENT}

I thank the St Vincent's Clinic Foundation Sydney and the Faculty of Medicine, SOMS, University of New South Wales, Australia for support.

\section{DISCLOSURE/CONFLICT OF INTEREST}

The author declares no conflict of interest.

1. Banchereau J, Steinman RM. Dendritic cells and control of immunity. Nature 1998;392:245-252.
2. Steinman RM, Cohn ZA. Identification of a novel cell type in peripheral lymphoid organs of mice. I. Morphology, quantification, tissue distribution. J Exp Med 1973;137:1142-1162.

3. Lotze MT, Thomson AW. Dendritic cells: Biology and Clinical Applications, 2nd edn. Academic Press: San Diego, CA, 2001.

4. Steinman RM. Dendritic cells: versatile controllers of the immune system. Nat Med 2007;13:1155-1159.

5. Steinman RM. Dendritic cells: understanding immunogenicity. Eur J Immunol 2007:37(Suppl 1):S53-S60.

6. Steinman RM, Banchereau J. Taking dendritic cells into medicine. Nature 2007;449:419-426.

7. Blanco P, Palucka AK, Pascual V, et al. Dendritic cells and cytokines in human inflammatory and autoimmune diseases. Cytokine Growth Factor Rev 2008;19:41-52.

8. Granucci F, Zanoni I, Ricciardi-Castagnoli P. Central role of dendritic cells in the regulation and deregulation of immune responses. Cell Mol Life Sci 2008;65:1683-1697.

9. Mortellaro A, Conforti-Andreoni C, Fric J, et al. Dendritic cells as sensors of environmental perturbations. Microbes Infect 2008;10:990-994.

10. Gee K, Guzzo C, Che Mat NF, et al. The IL-12 family of cytokines in infection, inflammation and autoimmune disorders. Inflamm Allergy Drug Targets 2009;8:40-52.

11. Yamazaki S, Steinman RM. Dendritic cells as controllers of antigenspecific Foxp3+ regulatory T cells. J Dermatol Sci 2009;54:69-75.

12. Bobryshev YV, Lord RSA. Ultrastructural recognition of cells with dendritic cell morphology in human aortic intima. Contacting interactions of vascular dendritic cells in athero-resistant and athero-prone areas of the normal aorta. Arch Histol Cytol 1995;58: 307-322.

13. Bobryshev YV. Dendritic cells in atherosclerosis: current status of the problem and clinical relevance. Eur Heart J 2005;26:1700-1704.

14. Robertson AK, Hansson GK. T cells in atherogenesis: for better or for worse? Arterioscler Thromb Vasc Biol 2006;26:2421-2432.

15. Doherty TM, Fisher EA, Arditi M. TLR signaling and trapped vascular dendritic cells in the development of atherosclerosis. Trends Immunol 2006;27:222-227.

16. Randolph GJ. Emigration of monocyte-derived cells to lymph nodes during resolution of inflammation and its failure in atherosclerosis. Curr Opin Lipidol 2008;19:462-468.

17. Galkina E, Ley K. Leukocyte influx in atherosclerosis. Curr Drug Targets 2007;8:1239-1248.

18. Weber C, Zernecke A, Libby P. The multifaceted contributions of leukocyte subsets to atherosclerosis: lessons from mouse models. Nat Rev Immunol 2008;8:802-815.

19. Gawaz M, Stellos K, Langer HF. Platelets modulate atherogenesis and progression of atherosclerotic plaques via interaction with progenitor and dendritic cells. J Thromb Haemost 2008;6:235-242.

20. Galkina $E$, Ley K. Immune and inflammatory mechanisms of atherosclerosis. Annu Rev Immunol 2009;27:165-197.

21. Shimada K. Immune system and atherosclerotic disease. Heterogeneity of leukocyte subsets participating in the pathogenesis of atherosclerosis. Circ J 2009;73:994-1001.

22. Smid J, Berger A, Braun-Dullaeus R, et al. Impact of dendritic cells on vascular biology. Curr Hypertension Rev 2009;5:49-53.

23. Soehnlein $\mathrm{O}$, Weber $\mathrm{C}$. Myeloid cells in atherosclerosis: initiators and decision shapers. Semin Immunopathol 2009;31:35-47.

24. Niessner A, Weyand CM. Dendritic cells in atherosclerotic disease. Clin Immunol 2009;134:25-32.

25. Naik SH, Metcalf $D$, van Nieuwenhuijze $A$, et al. Intrasplenic steadystate dendritic cell precursors that are distinct from monocytes. Nat Immunol 2006;7:663-671.

26. Shortman K, Naik SH. Steady-state and inflammatory dendritic-cell development. Nat Rev Immunol 2007;7:19-30.

27. Lin KW, Jacek T, Jacek R. Dendritic cells heterogeneity and its role in cancer immunity. J Cancer Res Ther 2006;2:35-40.

28. Ueno $\mathrm{H}$, Klechevsky $\mathrm{E}$, Morita $\mathrm{R}$, et al. Dendritic cell subsets in health and disease. Immunol Rev 2007;219:118-142.

29. Wilson NS, El-Sukkari D, Belz GT, et al. Most lymphoid organ dendritic cell types are phenotypically and functionally immature. Blood 2003;102:2187-2194.

30. Auffray C, Sieweke MH, Geissmann F. Blood monocytes: development, heterogeneity, and relationship with dendritic cells. Annu Rev Immunol 2009;27:669-692. 
31. Grouard G, Rissoan MC, Filgueira L, et al. The enigmatic plasmacytoid T cells develop into dendritic cells with interleukin (IL)-3 and CD40ligand. J Exp Med 1997;185:1101-1111.

32. León B, Ardavín C. Monocyte-derived dendritic cells in innate and adaptive immunity. Immunol Cell Biol 2008;86:320-324.

33. Libby $P$, Nahrendorf $M$, Pittet MJ, et al. Diversity of denizens of the atherosclerotic plaque: not all monocytes are created equal. Circulation 2008;117:3168-3170.

34. Köhl J. Self, non-self, and danger: a complementary view. Adv Exp Med Biol 2006;586:71-94.

35. Ruco LP, Uccini S, Baroni CD. The Langerhans' cells. Allergy 1989;44(Suppl 9):27-30.

36. Hoefsmit EC, Duijvestijn AM, Kamperdijk EW. Relation between Langerhans cells, veiled cells, and interdigitating cells. Immunobiology 1982;161:255-265.

37. Kobayashi M, Asano H, Fujita $\mathrm{Y}$, et al. Development of ATPasepositive, immature Langerhans cells in the fetal mouse epidermis and their maturation during the early postnatal period. Cell Tissue Res 1987;248:315-322.

38. Kashihara $M$, Ueda $M$, Horiguchi $Y$, et al. A monoclonal antibody specifically reactive to human Langerhans cells. J Invest Dermatol 1986;87:602-607.

39. Fujita M, Kashihara-Sawami M, Horiguchi $Y$, et al. Langerhans cells in human allergic contact dermatitis contain varying numbers of Birbeck granules. Double staining immunohistochemistry with OKT6 and Lag antibody. Histochemistry 1990;94:497-504.

40. Hanau D, Fabre M, Schmitt DA, et al. Human epidermal Langerhans cells cointernalize by receptor-mediated endocytosis 'nonclassical' major histocompatibility complex class I molecules (T6 antigens) and class II molecules (HLA-DR antigens). Proc Natl Acad Sci USA 1987;84:2901-2905.

41. Valladeau J, Ravel O, Dezutter-Dambuyant C, et al. Langerin, a novel C-type lectin specific to Langerhans cells, is an endocytotic receptor that induces the formation of Birbeck granules. Immunity 2000;12:71-81.

42. Valladeau J, Dezutter-Dambuyant C, Saeland S. Langerin/CD207 sheds light on formation of Birbeck granules and their possible function in Langerhans cells. Immunol Res 2003;28:93-107.

43. Turley SJ, Inaba K, Garrett WS, et al. Transport of peptide-MHC class II complexes in developing dendritic cells. Science 2000;288: 522-527.

44. Santambrogio L, Sato AK, Fischer FR, et al. Abundant empty class II $\mathrm{MHC}$ molecules on the surface of immature dendritic cells. Proc Natl Acad Sci USA 1999;96:15050-15055.

45. Davoust J, Banchereau J. Naked antigen-presenting molecules on dendritic cells. Nat Cell Biol 2000;2:E46-E48.

46. Ahmed KA, Munegowda MA, Xie $Y$, et al. Intercellular trogocytosis plays an important role in modulation of immune responses. Cell Mol Immunol 2008;5:261-269.

47. Berchtold $\mathrm{S}$, Mühl-Zürbes $\mathrm{P}$, Maczek $\mathrm{E}$, et al. Cloning and characterization of the promoter region of the human CD83 gene. Immunobiology 2002;205:231-246.

48. Lechmann M, Zinser E, Golka A, et al. Role of CD83 in the immunomodulation of dendritic cells. Int Arch Allergy Immunol 2002;129:113-118.

49. Bobryshev YV, Lord RS. S-100 positive cells in human arterial intima and in atherosclerotic lesions. Cardiovasc Res 1995;29:689-696.

50. Bobryshev YV, Lord RS. Langhans cells of human arterial intima: uniform by stellate appearance but different by nature. Tissue Cell 1996;28:177-194.

51. Waltner-Romen M, Falkensammer G, Rabl W, et al. A previously unrecognized site of local accumulation of mononuclear cells. The vascular-associated lymphoid tissue. J Histochem Cytochem 1998;46:1347-1350.

52. Millonig G, Niederegger $\mathrm{H}$, Rabl W, et al. Network of vascularassociated dendritic cells in intima of healthy young individuals. Arterioscler Thromb Vasc Biol 2001;21:503-508.

53. Ma-Krupa W, Jeon MS, Spoerl S, et al. Activation of arterial wall by dendritic cells and breakdown of self-tolerance in giant cell arteritis. J Exp Med 2004;199:173-183.

54. Galkina E, Kadl A, Sanders J, et al. Lymphocyte recruitment into the aortic wall before and during development of atherosclerosis is partially L-selectin dependent. J Exp Med 2006;203:1273-1282.
55. Bobryshev YV, Lord RS, Watanabe T. Structural peculiarities of vascular dendritic cell tubulovesicular system in human atherosclerotic aorta. J Submicrosc Cytol Pathol 1997;29:553-561.

56. Bobryshev YV, Lord RS. Structural heterogeneity and contacting interactions of vascular dendritic cells in early atherosclerotic lesions of the human aorta. J Submicrosc Cytol Pathol 1996;28:49-60.

57. Bobryshev YV, Ikezawa T, Watanabe T. Formation of Birbeck granulelike structures in vascular dendritic cells in human atherosclerotic aorta. Lag-antibody to epidermal Langerhans cells recognizes cells in the aortic wall. Atherosclerosis 1997;133:193-202.

58. Wick G, Knoflach $M$, Xu Q. Autoimmune and inflammatory mechanisms in atherosclerosis. Annu Rev Immunol 2004;22:361-364.

59. Bacci S, Pieri L, Buccoliero AM, et al. Smooth muscle cells, dendritic cells and mast cells are sources of TNF alpha and nitric oxide in human carotid artery atherosclerosis. Thromb Res 2008;122: 657-667.

60. Bobryshev YV, Lord RSA. Mapping of vascular dendritic cells in atherosclerotic arteries suggests their involvement in local immuneinflammatory reactions. Cardiovasc Res 1998;37:799-810.

61. Yilmaz A, Lochno $M$, Traeg $F$, et al. Emergence of dendritic cells in rupture-prone regions of vulnerable carotid plaques. Atherosclerosis 2004;176:101-110.

62. Erbel C, Sato K, Meyer FB, et al. Functional profile of activated dendritic cells in unstable atherosclerotic plaque. Basic Res Cardiol 2007;102:123-132.

63. Bobryshev YV, Lord RS, Rainer S, et al. Vascular dendritic cells and atherosclerosis. Pathol Res Pract 1996;192:462-467.

64. Bobryshev YV, Lord RS. 55-kD actin-bundling protein ( $p 55$ ) is a specific marker for identifying vascular dendritic cells. J Histochem Cytochem 1999;47:1481-1486.

65. Soilleux EJ, Morris LS, Trowsdale J, et al. Human atherosclerotic plaques express DC-SIGN, a novel protein found on dendritic cells and macrophages. J Pathol 2002;198:511-516.

66. Spanbroek R, Grabner R, Lotzer K, et al. Expanding expression of the 5-lipoxygenase pathway within the arterial wall during human atherogenesis. Proc Natl Acad Sci USA 2003;100:1238-1243.

67. Kawahara I, Kitagawa N, Tsutsumi K, et al. The expression of vascular dendritic cells in human atherosclerotic carotid plaques. Hum Pathol 2007;38:1378-1385.

68. Millonig G, Malcom GT, Wick G. Early inflammatory-immunological lesions in juvenile atherosclerosis from the Pathobiological Determinants of Atherosclerosis in Youth (PDAY)-study. Atherosclerosis 2002;160:441-448.

69. Melian A, Geng YJ, Sukhova GK, et al. CD1 expression in human atherosclerosis. A potential mechanism for $T$ cell activation by foam cells. Am J Pathol 1999;15:775-786.

70. Bobryshev YV, Lord RS. CD1 expression and the nature of CD1expressing cells in human atherosclerotic plaques. Am J Pathol 2000;156:1477-1478.

71. Brigl M, Brenner MB. CD1: antigen presentation and T cell function. Annu Rev Immunol 2004;22:817-890.

72. Gelin C, Sloma I, Charron D, et al. Regulation of MHC II and CD1 antigen presentation: from ubiquity to security. J Leukoc Biol 2009;85:215-224.

73. Bobryshev YV, Lord RSA. Co-accumulation of dendritic cells and natural killer $\mathrm{T}$ cells within rupture-prone regions in human atherosclerotic plaques. J Histochem Cytochem 2005;53:781-785.

74. Bobryshev YV. Natural killer T cells in atherosclerosis. Arterioscler Thromb Vasc Biol 2005;25:e40.

75. Jongstra-Bilen J, Haidari M, Zhu SN, et al. Low-grade chronic inflammation in regions of the normal mouse arterial intima predisposed to atherosclerosis. J Exp Med 2006;203:2073-2083.

76. Choi JH, Do Y, Cheong C, et al. Identification of antigen-presenting dendritic cells in mouse aorta and cardiac valves. J Exp Med 2009;206:497-505.

77. Gautier EL, Huby T, Saint-Charles F, et al. Conventional dendritic cells at the crossroads between immunity and cholesterol homeostasis in atherosclerosis. Circulation 2009;119:2367-2375.

78. Randolph GJ, Beaulieu S, Lebecque S, et al. Differentiation of monocytes into dendritic cells in a model of transendothelial trafficking. Science 1998;282:480-483.

79. Bobryshev YV. Monocyte recruitment and foam cell formation in atherosclerosis. Micron 2006;37:208-222. 
80. Bobryshev YV, Lord RS. Vascular-associated lymphoid tissue (VALT) involvement in aortic aneurysm. Atherosclerosis 2001; 154:15-21.

81. Shen LH, Zhou L, Wang BY, et al. Oxidized low-density lipoprotein induces differentiation of RAW264.7 murine macrophage cell line into dendritic-like cells. Atherosclerosis 2008;199:257-264.

82. Wick $G$, Romen $M$, Amberger $A$, et al. Atherosclerosis, autoimmunity, and vascular-associated lymphoid tissue. FASEB J 1997;11: 1199-1207.

83. Dhodapkar MV, Steinman RM, Krasovsky J, et al. Antigen-specific inhibition of effector $T$ cell function in humans after injection of immature dendritic cells. J Exp Med 2001;193:233-238.

84. Pisetsky DS. The role of innate immunity in the induction of autoimmunity. Autoimmun Rev 2008;8:69-72.

85. Lord RS, Bobryshev YV. Clustering of dendritic cells in athero-prone areas of the aorta. Atherosclerosis 1999;146:197-198.

86. Bobryshev YV, Babaev VR, Iwasa S, et al. Atherosclerotic lesions of apolipoprotein $\mathrm{E}$ deficient mice contain cells expressing $\mathrm{S} 100$ protein. Atherosclerosis 1999;143:451-454.

87. Bobryshev YV, Taksir T, Lord RS, et al. Evidence that dendritic cells infiltrate atherosclerotic lesions in apolipoprotein E-deficient mice. Histol Histopathol 2001;16:801-808.

88. Ozmen J, Bobryshev YV, Lord RS, et al. Identification of dendritic cells in aortic atherosclerotic lesions in rats with diet-induced hypercholesterolaemia. Histol Histopathol 2002;17:223-237.

89. Aicher A, Heeschen $C$, Mohaupt $M$, et al. Nicotine strongly activates dendritic cell-mediated adaptive immunity: potential role for progression of atherosclerotic lesions. Circulation 2003;107: 604-611.

90. Afek A, Harats D, Roth A, et al. Evidence for the involvement of T cell costimulation through the B-7/CD28 pathway in atherosclerotic plaques from apolipoprotein E knockout mice. Exp Mol Pathol 2004;76:219-223.

91. Shaposhnik Z, Wang X, Weinstein M, et al. Granulocyte macrophage colony-stimulating factor regulates dendritic cell content of atherosclerotic lesions. Arterioscler Thromb Vasc Biol 2007;27: 621-627.

92. Erbel C, Chen L, Bea $F$, et al. Inhibition of IL-17A attenuates atherosclerotic lesion development in apoE-deficient mice. $\mathrm{J}$ Immunol 2009;183:8167-8175.

93. Paulson KE, Zhu SN, Chen M, et al. Resident intimal dendritic cells accumulate lipid and contribute to the initiation of atherosclerosis. Circ Res 2010;106:383-390.

94. Ludewig $B$, Freigang $S$, Jäggi $M$, et al. Linking immune-mediated arterial inflammation and cholesterol-induced atherosclerosis in a transgenic mouse model. Proc Natl Acad Sci USA 2000;97: 12752-12757.

95. Angeli V, Llodrá J, Rong JX, et al. Dyslipidemia associated with atherosclerotic disease systemically alters dendritic cell mobilization. Immunity 2004;21:561-574.

96. Packard RR, Maganto-García E, Gotsman I, et al. CD11c(+) dendritic cells maintain antigen processing, presentation capabilities, and CD4(+) T-cell priming efficacy under hypercholesterolemic conditions associated with atherosclerosis. Circ Res 2008;103:965-973.

97. Liu P, Yu YR, Spencer JA, et al. CX3CR1 deficiency impairs dendritic cell accumulation in arterial intima and reduces atherosclerotic burden. Arterioscler Thromb Vasc Biol 2008;28:243-250.

98. Habets $\mathrm{KL}$, van Puijvelde GH, van Duivenvoorde LM, et al. Vaccination using oxidized low-density lipoprotein-pulsed dendritic cells reduces atherosclerosis in LDL receptor-deficient mice. Cardiovasc Res 2010;85:622-630.

99. Hjerpe C, Johansson D, Hermansson A, et al. Dendritic cells pulsed with malondialdehyde modified low density lipoprotein aggravate atherosclerosis in ApoE (-/-) mice. Atherosclerosis 2010;209:436-441.

100. van Es $T$, van Puijvelde $G H$, Foks $A C$, et al. Vaccination against Foxp3(+) regulatory $\mathrm{T}$ cells aggravates atherosclerosis. Atherosclerosis 2010;209:74-80.

101. Weis $\mathrm{M}$, Schlichting $\mathrm{CL}$, Engleman EG, et al. Endothelial determinants of dendritic cell adhesion and migration: new implications for vascular diseases. Arterioscler Thromb Vasc Biol 2002;22:1817-1823.

102. Zhu WG, Li S, Lin LQ, et al. Vascular oxidative stress increases dendritic cell adhesion and transmigration induced by homocysteine. Cell Immunol 2009;254:110-116.
103. Zaguri R, Verbovetski I, Atallah M, et al. 'Danger' effect of low-density lipoprotein (LDL) and oxidized LDL on human immature dendritic cells. Clin Exp Immunol 2007;149:543-552.

104. Leitinger $\mathrm{N}$. The role of phospholipid oxidation products in inflammatory and autoimmune diseases: evidence from animal models and in humans. Subcell Biochem 2008;49:325-350.

105. Zitvogel L, Kroemer G. Introduction: the immune response against dying cells. Curr Opin Immunol 2008;20:501-503.

106. Lee J, Zhuang Y, Wei X, et al. Contributions of PD-1/PD-L1 pathway to interactions of myeloid DCs with T cells in atherosclerosis. J Mol Cell Cardiol 2009;46:169-176.

107. Bobryshev YV, Lord RS, Warren BA. Calcified deposit formation in intimal thickenings of the human aorta. Atherosclerosis 1995; 118:9-21.

108. Ross R. Atherosclerosis-an inflammatory disease. N Engl J Med 1999;340:115-126.

109. Bobryshev YV, Babaev VR, Lord RS, et al. Cell death in atheromatous plaque of the carotid artery occurs through necrosis rather than apoptosis. In Vivo 1997;11:441-452.

110. Leinonen M, Saikku P. Evidence for infectious agents in cardiovascular disease and atherosclerosis. Lancet Infect Dis 2002;2:11-17.

111. Kis Z, Pallinger E, Endresz V, et al. The interactions between human dendritic cells and microbes; possible clinical applications of dendritic cells. Inflamm Res 2004;53:413-423.

112. Bobryshev YV, Cao W, Phoon MC, et al. Detection of Chlamydophila pneumoniae in dendritic cells in atherosclerotic lesions. Atherosclerosis 2004;173:185-195.

113. Varga T, Nagy L. Nuclear receptors, transcription factors linking lipid metabolism and immunity: the case of peroxisome proliferatoractivated receptor gamma. Eur J Clin Invest 2008;38:695-707.

114. Szatmari I, Nagy L. Nuclear receptor signalling in dendritic cells connects lipids, the genome and immune function. EMBO J 2008;27:2353-2362.

115. Tobias PS, Curtiss LK. Toll-like receptors in atherosclerosis. Biochem Soc Trans 2007;35(Part 6):1453-1455.

116. Netea MG, van der Graaf C, Van der Meer JW, et al. Toll-like receptors and the host defense against microbial pathogens: bringing specificity to the innate-immune system. J Leukoc Biol 2004;75: 749-755.

117. Niessner A, Shin MS, Pryshchep O, et al. Synergistic proinflammatory effects of the antiviral cytokine interferon-alpha and Toll-like receptor 4 ligands in the atherosclerotic plaque. Circulation 2007;116: 2043-2052.

118. Wang L, Li D, Yang K, et al. Toll-like receptor-4 and mitogen-activated protein kinase signal system are involved in activation of dendritic cells in patients with acute coronary syndrome. Immunology 2008;125:122-130.

119. Han JW, Shimada K, Ma-Krupa W, et al. Vessel wall-embedded dendritic cells induce T-cell autoreactivity and initiate vascular inflammation. Circ Res 2008;102:546-553.

120. Shamshiev AT, Ampenberger F, Ernst B, et al. Dyslipidemia inhibits Toll-like receptor-induced activation of CD8alpha-negative dendritic cells and protective Th1 type immunity. J Exp Med 2007;204:441-452.

121. Pryshchep O, Ma-Krupa W, Younge BR, et al. Vessel-specific Toll-like receptor profiles in human medium and large arteries. Circulation 2008:118:1276-1284.

122. Curtiss LK, Tobias PS. The toll of Toll-like receptors, especially toll-like receptor 2, on murine atherosclerosis. Curr Drug Targets 2007;8:1230-1238.

123. $\mathrm{Yi} \mathrm{H}, \mathrm{Yu} \mathrm{X}, \mathrm{Gao} P$, et al. Pattern recognition scavenger receptor SRA/ CD204 down-regulates Toll-like receptor 4 signaling-dependent CD8 T-cell activation. Blood 2009;113:5819-5828.

124. Nickel $T$, Schmauss $D$, Hanssen $H$, et al. oxLDL uptake by dendritic cells induces upregulation of scavenger-receptors, maturation and differentiation. Atherosclerosis 2009;205:442-450.

125. Perrin-Cocon L, Coutant F, Agaugue $S$, et al. Oxidized low-density lipoprotein promotes mature dendritic cell transition from differentiating monocyte. J Immunol 2001;167:3785-3791.

126. Alderman CJ, Bunyard PR, Chain BM, et al. Effects of oxidised low density lipoprotein on dendritic cells: a possible immunoregulatory component of the atherogenic micro-environment? Cardiovasc Res 2002;55:806-819. 
127. Bobryshev YV, Watanabe T. Subset of vascular dendritic cells transforming into foam cells in human atherosclerotic lesions. Cardiovasc Pathol 1997;6:321-331.

128. Woszczek G, Chen LY, Nagineni S, et al. IL-10 inhibits cysteinyl leukotriene-induced activation of human monocytes and monocytederived dendritic cells. J Immunol 2008;180:7597-7603.

129. Van Vré EA, Bult H, Hoymans VY, et al. Human C-reactive protein activates monocyte-derived dendritic cells and induces dendritic cell-mediated T-cell activation. Arterioscler Thromb Vasc Biol 2008;28:511-518.

130. Naiki $\mathrm{Y}$, Sorrentino $\mathrm{R}$, Wong $\mathrm{MH}$, et al. TLR/MyD88 and liver $\mathrm{X}$ receptor alpha signaling pathways reciprocally control Chlamydia pneumoniae-induced acceleration of atherosclerosis. J Immunol 2008;181:7176-7185.

131. Ibeas E, Fuentes L, Martín R, et al. Secreted phospholipase A2 type IIA as a mediator connecting innate and adaptive immunity: new role in atherosclerosis. Cardiovasc Res 2009;81:54-63.

132. Wilhelm AJ, Zabalawi M, Grayson JM, et al. Apolipoprotein A-I and its role in lymphocyte cholesterol homeostasis and autoimmunity. Arterioscler Thromb Vasc Biol 2009;29:843-849.

133. Shi HY, Ge JB, Fang WY, et al. Peroxisome proliferator-activated receptor $\alpha$ agonist attenuates oxidized-low density lipoprotein induced maturation of human monocyte-derived dendritic cells. Chin Med J (Engl) 2008;121:1747-1750.

134. Luo $Y$, Liang $C, X u C$, et al. Ciglitazone inhibits oxidized-low density lipoprotein induced immune maturation of dendritic cells. J Cardiovasc Pharmacol 2004;44:381-385.

135. Ge J, Jia Q, Liang C, et al. Advanced glycosylation end products might promote atherosclerosis through inducing the immune maturation of dendritic cells. Arterioscler Thromb Vasc Biol 2005;25:2157-2163.

136. Bosco MC, Puppo M, Blengio F, et al. Monocytes and dendritic cells in a hypoxic environment: spotlights on chemotaxis and migration. Immunobiology 2008;213:733-749.

137. Elia AR, Cappello $P$, Puppo $M$, et al. Human dendritic cells differentiated in hypoxia down-modulate antigen uptake and change their chemokine expression profile. J Leukoc Biol 2008;84:1472-1482.

138. Burke DL, Frid MG, Kunrath $\mathrm{CL}$, et al. Sustained hypoxia promotes the development of a pulmonary artery-specific chronic inflammatory microenvironment. Am J Physiol Lung Cell Mol Physiol 2009;297:L238-L250.

139. Bobryshev YV, Lord RS. Expression of heat shock protein-70 by dendritic cells in the arterial intima and its potential significance in atherogenesis. J Vasc Surg 2002;35:368-375.

140. Yilmaz A, Lipfert B, Cicha I, et al. Accumulation of immune cells and high expression of chemokines/chemokine receptors in the upstream shoulder of atherosclerotic carotid plaques. Exp Mol Pathol 2007;82:245-255.

141. Springer TA. Traffic signals for lymphocyte recirculation and leukocyte emigration: the multistep paradigm. Cell 1994;76:301-314.

142. Ozmen J, Bobryshev YV, Lord RS. CD40 co-stimulatory molecule expression by dendritic cells in primary atherosclerotic lesions in carotid arteries and in stenotic saphenous vein coronary artery grafts. Cardiovasc Surg 2001;9:329-333.

143. Llodra J, Angeli V, Liu J, et al. Emigration of monocyte-derived cells from atherosclerotic lesions characterizes regressive, but not progressive, plaques. Proc Natl Acad Sci USA 2004;101:11779-11784.

144. Stemme S, Rymo L, Hansson GK. Polyclonal origin of T lymphocytes in human atherosclerotic plaques. Lab Invest 1991;65:654-660.

145. Bobryshev YV, Watanabe T. Ultrastructural evidence for association of vascular dendritic cells with T-lymphocytes and with B-cells in human atherosclerosis. J Submicrosc Cytol Pathol 1997;29:209-221.

146. Castellano G, Woltman AM, Schena FP, et al. Dendritic cells and complement: at the cross road of innate and adaptive immunity. Mol Immunol 2004;41:133-140.

147. van Kooten C, Fiore N, Trouw LA, et al. Complement production and regulation by dendritic cells: molecular switches between tolerance and immunity. Mol Immunol 2008;45:4064-4072.
148. Cao W, Bobryshev YV, Lord RS, et al. Dendritic cells in the arterial wall express C1q: potential significance in atherogenesis. Cardiovasc Res 2003:60:175-186.

149. Yilmaz A, Reiss C, Weng A, et al. Differential effects of statins on relevant functions of human monocyte-derived dendritic cells. J Leukoc Biol 2006;79:529-538.

150. Yilmaz A, Reiss C, Tantawi O, et al. HMG-CoA reductase inhibitors suppress maturation of human dendritic cells: new implications for atherosclerosis. Atherosclerosis 2004;172:85-93.

151. Kofler S, Schlichting C, Jankl S, et al. Dual mode of HMG-CoA reductase inhibition on dendritic cell invasion. Atherosclerosis 2008;197:105-110.

152. Yilmaz A, Weber J, Cicha I, et al. Decrease in circulating myeloid dendritic cell precursors in coronary artery disease. J Am Coll Cardiol 2006;48:70-80.

153. Yilmaz A, Fuchs $T$, Dietel $B$, et al. Transient decrease in circulating dendritic cell precursors after acute stroke-potential recruitment into the brain. Clin Sci (Lond) 2009;118:147-157.

154. Van Vré EA, Hoymans VY, Bult $\mathrm{H}$, et al. Decreased number of circulating plasmacytoid dendritic cells in patients with atherosclerotic coronary artery disease. Coron Artery Dis 2006;17:243-248.

155. Madjid M, Vela D, Khalili-Tabrizi $H$, et al. Systemic infections cause exaggerated local inflammation in atherosclerotic coronary arteries: clues to the triggering effect of acute infections on acute coronary syndromes. Tex Heart Inst J 2007;34:11-18.

156. Ranjit S, Dazhu L, Qiutang Z, et al. Differentiation of dendritic cells in monocyte cultures isolated from patients with unstable angina. Int J Cardiol 2004;97:551-555.

157. Dopheide JF, Sester U, Schlitt A, et al. Monocyte-derived dendritic cells of patients with coronary artery disease show an increased expression of costimulatory molecules CD40, CD80 and CD86 in vitro. Coron Artery Dis 2007;18:523-531.

158. Binder CJ, Hartvigsen K, Witztum JL. Promise of immune modulation to inhibit atherogenesis. J Am Coll Cardiol 2007;50:547-550.

159. Hansson GK, Nilsson J. Vaccination against atherosclerosis? Induction of atheroprotective immunity. Semin Immunopathol 2009;31:95-101.

160. Bobryshev YV. Can dendritic cells be exploited for therapeutic intervention in atherosclerosis? Atherosclerosis 2001;154:511-512.

161. Timmerman JM, Levy R. Dendritic cell vaccines for cancer immunotherapy. Annu Rev Med 1999;50:507-529.

162. Markiewicz MA, Kast WM. Progress in the development of immunotherapy of cancer using ex vivo-generated dendritic cells expressing multiple tumor antigen epitopes. Cancer Invest 2004;22:417-434.

163. Dubsky $P$, Ueno $H$, Piqueras $B$, et al. Human dendritic cell subsets for vaccination. J Clin Immunol 2005;25:551-572.

164. Palucka AK, Ueno H, Fay JW, et al. Taming cancer by inducing immunity via dendritic cells. Immunol Rev 2007;220:129-150.

165. Steinman RM. Dendritic cells in vivo: a key target for a new vaccine science. Immunity 2008;29:319-324.

166. Benko S, Magyarics Z, Szabó A, et al. Dendritic cell subtypes as primary targets of vaccines: the emerging role and cross-talk of pattern recognition receptors. Biol Chem 2008;389: 469-485.

167. Nilsson J, Nordin Fredrikson G, Schiopu A, et al. Oxidized LDL antibodies in treatment and risk assessment of atherosclerosis and associated cardiovascular disease. Curr Pharm Des 2007;13: 1021-1030.

168. Fredrikson GN, Björkbacka $\mathrm{H}$, Söderberg I, et al. Treatment with apo B peptide vaccines inhibits atherosclerosis in human apo B-100 transgenic mice without inducing an increase in peptide-specific antibodies. J Intern Med 2008;264:563-570.

169. van Leeuwen M, Damoiseaux J, Duijvestijn A, et al. The therapeutic potential of targeting $B$ cells and anti-oxLDL antibodies in atherosclerosis. Autoimmun Rev 2009;9:53-57. 